\title{
Scalable biomimetic syntheses of paeciloketal B, 1-epi-paeciloketal B and bysspectin A
}

Emma K. Davison, ${ }^{\dagger \S}$ Caitlin E. Shepperson ${ }^{\dagger}$ Zoe E. Wilson $^{\dagger \S}$ and Margaret A. Brimble $₫ \S^{*}$

$†$ School of Chemical Sciences, University of Auckland, 23 Symonds St., Auckland, 1010, New Zealand *School of Biological Sciences, University of Auckland, 3 Symonds St., Auckland, 1010, New Zealand §The Maurice Wilkins Centre for Molecular Biodiscovery, The University of Auckland, Private Bag 92019, Auckland, 1142, New Zealand

\section{SUPPORTING INFORMATION}




\section{TABLE OF CONTENTS}

$\begin{array}{ll}\text { Experimental Procedures } & \text { S3-4 }\end{array}$

Minimum inhibitory concentration assay protocols $\quad$ S5

Table S1 Minimum inhibitory concentration assay results $\quad$ S5

Table $\mathbf{S 2}{ }^{1} \mathrm{H}$ NMR comparison of natural $\mathbf{2}$ with synthetic $\mathbf{2} \quad$ S6

Table $\mathbf{S 3}{ }^{13} \mathrm{C}$ NMR comparison of natural $\mathbf{2}$ with synthetic $\mathbf{2} \quad$ S7

Table S4. ${ }^{1} \mathrm{H}$ NMR comparison of natural paeciloketal B $(( \pm)-1 \mathbf{a})$ with synthetic paeciloketal B (( \pm$)-\mathbf{1 a})$

Table S5. ${ }^{1} \mathrm{H}$ NMR comparison of natural 1-epi-paeciloketal B (( \pm$\left.)-1 \mathbf{b}\right)$ with synthetic 1epi-paeciloketal B $(( \pm)$-1b)

Table S6. ${ }^{13} \mathrm{C}$ NMR comparison of natural paeciloketal B ((土)-1a) with synthetic paeciloketal B (( \pm -1) $\mathbf{a})$

Table S7. ${ }^{13} \mathrm{C}$ NMR comparison of natural 1-epi-paeciloketal B (( \pm$\left.)-\mathbf{1 b}\right)$ with synthetic 1epi-paeciloketal B $(( \pm)-\mathbf{1 b})$

References

${ }^{1} \mathrm{H}$ NMR spectrum of $9 \quad$ S13

$\begin{array}{ll}{ }^{13} \mathrm{C} \text { NMR spectrum of } 9 & \text { S14 }\end{array}$

$\begin{array}{lr}{ }^{1} \mathrm{H} \text { NMR spectrum of bysspectin A (2) S15 } & \text { S }\end{array}$

${ }^{13} \mathrm{C}$ NMR spectrum of bysspectin A (2) $\quad$ S16

$\begin{array}{ll}{ }^{1} \mathrm{H} \text { NMR spectrum of } \mathbf{1 3} & \text { S17 }\end{array}$

$\begin{array}{ll}{ }^{13} \mathrm{C} \text { NMR spectrum of } \mathbf{1 3} & \text { S18 }\end{array}$

$\begin{array}{lr}{ }^{1} \mathrm{H} \text { NMR spectrum of } \mathbf{1 6} & \text { S19 }\end{array}$

$\begin{array}{lr}{ }^{13} \mathrm{C} \text { NMR spectrum of } \mathbf{1 6} & \text { S20 }\end{array}$

$\begin{array}{ll}{ }^{1} \mathrm{H} \text { NMR spectrum of } \mathbf{1 4} & \text { S21 }\end{array}$

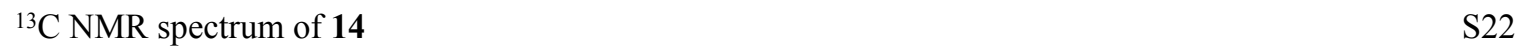

$\begin{array}{ll}{ }^{1} \mathrm{H} \text { NMR spectrum of } \mathbf{1 5} & \text { S23 }\end{array}$

${ }^{13} \mathrm{C}$ NMR spectrum of $\mathbf{1 5} \quad$ S24

$\begin{array}{lr}{ }^{1} \mathrm{H} \text { NMR spectrum of } \mathbf{1 7} & \text { S25 }\end{array}$

${ }^{13} \mathrm{C}$ NMR spectrum of $\mathbf{1 7} \quad$ S26

$\begin{array}{ll}{ }^{1} \mathrm{H} \text { NMR spectrum of } \mathbf{1 8} & \text { S27 }\end{array}$

${ }^{13} \mathrm{C}$ NMR spectrum of $\mathbf{1 8} \quad$ S28

$\begin{array}{lr}{ }^{1} \mathrm{H} \text { NMR spectrum of } \mathbf{1 1} & \text { S29 }\end{array}$

$\begin{array}{ll}{ }^{13} \mathrm{C} \text { NMR spectrum of } \mathbf{1 1} & \text { S30 }\end{array}$

${ }^{1} \mathrm{H}$ NMR spectrum of $\mathbf{1 9} \quad$ S31

${ }^{13} \mathrm{C}$ NMR spectrum of $\mathbf{1 9} \quad$ S32

$\begin{array}{ll}{ }^{1} \mathrm{H} \text { NMR spectrum of }(\mathrm{rac})-\mathbf{2 0} & \text { S33 }\end{array}$

${ }^{1}$ H NMR spectrum of paeciloketals $( \pm)-\mathbf{1 a}$ and $( \pm)-\mathbf{1 b}(11: 14) \quad$ S34

${ }^{13} \mathrm{C}$ NMR spectrum of paeciloketals $( \pm)-\mathbf{1 a}$ and $( \pm)-\mathbf{1 b}(11: 14) \quad$ S35

COSY spectrum of paeciloketals $( \pm)-\mathbf{1 a}$ and $( \pm)-\mathbf{1 b}(11: 14) \quad$ S36

edited-HSQC spectrum of paeciloketals $( \pm)-\mathbf{1 a}$ and $( \pm)-\mathbf{1 b}(11: 14) \quad$ S37 


\section{Experimental Procedures}

Scheme S1. Synthesis of 1-(2-iodo-3-methoxyphenyl)nonan-1-one (7) using literature methods.

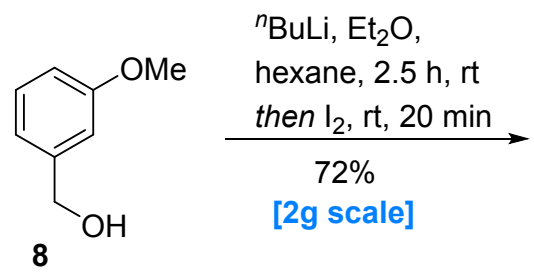<smiles>COc1cccc(CO)c1I</smiles>

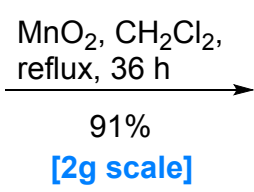<smiles>COc1cccc(C=O)c1I</smiles><smiles>COc1cccc(C(=O)O)c1I</smiles>

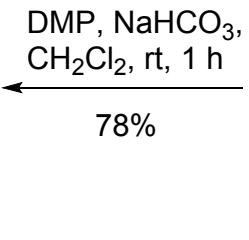

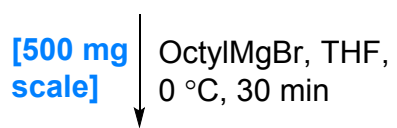<smiles>COc1cccc(C(O)C=[AsH2])c1I</smiles>

1-(2-Iodo-3-methoxyphenyl)nonan-1-one (7) was prepared (22\% overall yield, yellow oil) according to reported procedures from benzyl alcohol $\mathbf{8}$ in four steps, namely, iodination, ${ }^{1}$ oxidation, ${ }^{2}$ Grignard addition ${ }^{3}$ and oxidation ${ }^{3}$ (Scheme S1). $\delta_{\mathrm{H}}\left(400 \mathrm{MHz}, \mathrm{CDCl}_{3}\right) 7.33(1 \mathrm{H}, \mathrm{t}, J 7.7, \mathrm{CH}), 6.83(2 \mathrm{H}$, app. td, $J$ 8.5, 1.3, $2 \times \mathrm{CH}), 3.90(3 \mathrm{H}, \mathrm{s}$, $\left.\mathrm{OCH}_{3}\right), 2.86\left(2 \mathrm{H}, \mathrm{t}, J 7.4, \mathrm{CH}_{2}\right), 1.72\left(2 \mathrm{H}\right.$, pent, $\left.J 7.4, \mathrm{CH}_{2}\right), 1.39-1.27\left(10 \mathrm{H}, \mathrm{m}, 5 \times \mathrm{CH}_{2}\right), 0.88(3 \mathrm{H}, \mathrm{t}, J 6.9$, $\left.\mathrm{CH}_{3}\right) ; \delta_{\mathrm{C}}\left(100 \mathrm{MHz}, \mathrm{CDCl}_{3}\right) 206.5(\mathrm{C}), 158.3(\mathrm{C}), 148.7(\mathrm{C}), 129.7(\mathrm{CH}), 119.3(\mathrm{CH}), 111.7(\mathrm{CH}), 83.2(\mathrm{C}), 56.8$ $\left(\mathrm{OCH}_{3}\right), 42.9\left(\mathrm{CH}_{2}\right), 32.0\left(\mathrm{CH}_{2}\right), 29.5\left(\mathrm{CH}_{2}\right), 29.31\left(\mathrm{CH}_{2}\right), 29.27\left(\mathrm{CH}_{2}\right), 24.1\left(\mathrm{CH}_{2}\right), 22.8\left(\mathrm{CH}_{2}\right), 14.2\left(\mathrm{CH}_{3}\right) ; \mathrm{R}_{\mathrm{f}}$ 0.48 (petroleum ether-EtOAc, 4:1). Spectroscopic data is concordant with the literature. ${ }^{3}$

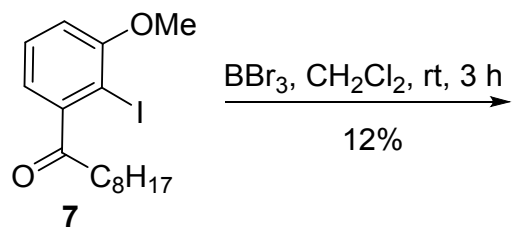<smiles>O=C(O)c1cccc(O)c1I</smiles>

Iodophenol 10 was prepared as a yellow oil $(17.5 \mathrm{mg}, 0.0486 \mathrm{mmol}, 12 \%)$ from methyl ether 7 according to the procedure described by Xie and coworkers. ${ }^{3} \delta_{\mathrm{H}}\left(400 \mathrm{MHz}, \mathrm{CDCl}_{3}\right) 7.27(1 \mathrm{H}, \mathrm{t}, J 7.8, \mathrm{CH}), 7.10(1 \mathrm{H}, \mathrm{dd}, J 8.0$, 1.5, CH), $6.97(1 \mathrm{H}, \mathrm{dd}, J 7.5,1.5, \mathrm{CH}), 5.97(1 \mathrm{H}, \mathrm{brs}, \mathrm{OH}), 2.87\left(2 \mathrm{H}, \mathrm{t}, J 7.5, \mathrm{CH}_{2}\right), 1.71\left(2 \mathrm{H}\right.$, pent, $\left.J 7.4, \mathrm{CH}_{2}\right)$, $1.38-1.25\left(10 \mathrm{H}, \mathrm{m}, 5 \times \mathrm{CH}_{2}\right), 0.88\left(3 \mathrm{H}, \mathrm{t}, J 6.9, \mathrm{CH}_{3}\right) ; \delta_{\mathrm{C}}\left(100 \mathrm{MHz}, \mathrm{CDCl}_{3}\right) 204.7(\mathrm{C}), 155.7(\mathrm{C}), 145.2(\mathrm{C})$, $129.9(\mathrm{CH}), 120.2(\mathrm{CH}), 117.0(\mathrm{CH}), 83.9(\mathrm{C}), 42.0\left(\mathrm{CH}_{2}\right), 32.0\left(\mathrm{CH}_{2}\right), 29.5\left(\mathrm{CH}_{2}\right), 29.34\left(\mathrm{CH}_{2}\right), 29.27\left(\mathrm{CH}_{2}\right)$, $24.3\left(\mathrm{CH}_{2}\right), 22.8\left(\mathrm{CH}_{2}\right), 14.2\left(\mathrm{CH}_{3}\right) ; \mathrm{R}_{\mathrm{f}} 0.25$ (petroleum ether-EtOAc, 4:1). Spectroscopic data is concordant with the literature. ${ }^{3}$

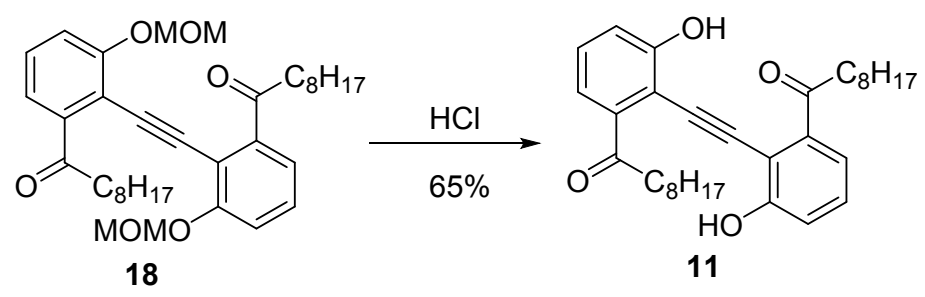

To a stirred solution of diarylalkyne $18(9.2 \mathrm{mg}, 0.0154 \mathrm{mmol})$ in $\mathrm{MeOH}-\mathrm{CH}_{2} \mathrm{Cl}_{2}(2: 1,0.9 \mathrm{~mL})$ was added conc. hydrochloric acid ( $37 \%$ aqueous, $0.06 \mathrm{~mL}$ ), and the resulting solution was stirred at room temperature for 4 hours open to air. Upon completion of the reaction, the solution was quenched with $\mathrm{H}_{2} \mathrm{O}(5 \mathrm{~mL})$ and extracted with $\mathrm{CH}_{2} \mathrm{Cl}_{2}(2 \times 10 \mathrm{~mL})$. The combined organic layers were dried using anhydrous $\mathrm{Na}_{2} \mathrm{SO}_{4}$, filtered, and concentrated in vacuo. The crude product was purified by flash chromatography on silica gel, eluting with petroleum ether - 
EtOAc (9:1) to afford diarylalkyne $11(4.9 \mathrm{mg}, 0.0100 \mathrm{mmol}, 65 \%)$ as a bright yellow amorphous solid. $\mathrm{v}_{\max } / \mathrm{cm}^{-1}$ (neat): $3387,3352,2919,2850,1670,1488,1460,1348,1301,1263,1245,1164,899,782,729 ; \delta_{\mathrm{H}}(500 \mathrm{MHz}$, $\left.\mathrm{CDCl}_{3}\right) 8.61(2 \mathrm{H}, \mathrm{s}, 2 \times \mathrm{OH}), 7.58(2 \mathrm{H}, \mathrm{dd}, J 7.9,1.2,2 \times \mathrm{CH}), 7.39(2 \mathrm{H}$, app. t, $J 7.9,2 \times \mathrm{CH}), 7.30(2 \mathrm{H}, \mathrm{dd}, J$ 8.5, 1.2, $2 \times \mathrm{CH}), 3.02\left(4 \mathrm{H}, \mathrm{t}, J 7.4,2 \times \mathrm{CH}_{2}\right), 1.78\left(4 \mathrm{H}\right.$, pent, $\left.J 7.5,2 \times \mathrm{CH}_{2}\right), 1.41-1.25\left(20 \mathrm{H}, \mathrm{m}, 10 \times \mathrm{CH}_{2}\right)$, $0.88\left(6 \mathrm{H}, \mathrm{t}, J 7.0,2 \times \mathrm{CH}_{3}\right) ; \delta_{\mathrm{C}}\left(125 \mathrm{MHz}, \mathrm{CDCl}_{3}\right) 200.5(2 \times \mathrm{C}), 160.1(2 \times \mathrm{C}), 136.4(2 \times \mathrm{C}), 129.8(2 \times \mathrm{CH})$, $122.0(2 \times \mathrm{CH}), 119.8(2 \times \mathrm{CH}), 108.1(2 \times \mathrm{C}), 96.0(2 \times \mathrm{C}), 39.7\left(2 \times \mathrm{CH}_{2}\right), 32.0\left(2 \times \mathrm{CH}_{2}\right), 29.6\left(2 \times \mathrm{CH}_{2}\right), 29.5$ $\left(2 \times \mathrm{CH}_{2}\right), 29.3\left(2 \times \mathrm{CH}_{2}\right), 24.8\left(2 \times \mathrm{CH}_{2}\right), 22.8\left(2 \times \mathrm{CH}_{2}\right), 14.3\left(2 \times \mathrm{CH}_{3}\right) ;$ HRMSESIMS m/z: $513.2963[\mathrm{M}+$ $\mathrm{Na}^{+}$(calcd for $\mathrm{C}_{32} \mathrm{H}_{42} \mathrm{O}_{4} \mathrm{Na}, 513.2975$ ); $\mathrm{R}_{\mathrm{f}} 0.64$ (petroleum ether-EtOAc, 4:1).

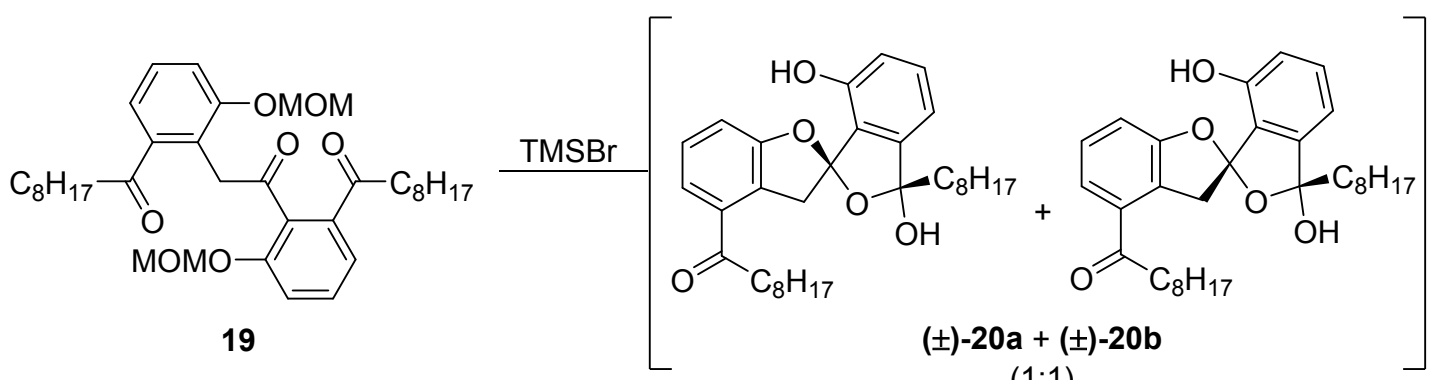

$(1: 1)$

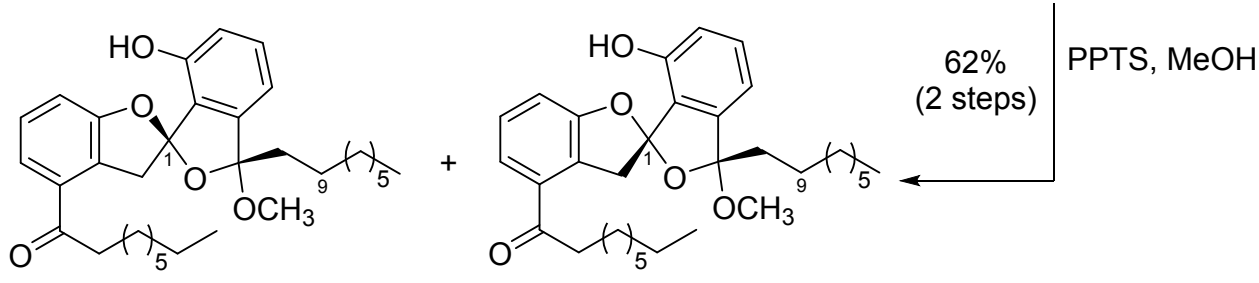

( \pm )-paeciloketal B (1a) : ( \pm )-1-epi-paeciloketal B (1b) $11: 14$

Hemiketals ( \pm )-20a and $( \pm)-20 b$ : Hemiketals ( $r a c)-20$ were found to be semi-stable; neat storage in the freezer led to degradation of the sample after several days. Owing to the observed instability of the material, complete characterisation of this compound could not be conducted, and it was subsequently used directly in the next step without purification. $\delta_{\mathrm{H}}\left(400 \mathrm{MHz}\right.$, methanol- $\left.\mathrm{d}_{4}\right) 7.55(2 \mathrm{H}, \mathrm{dd}, J 7.9,2.9,2 \times \mathrm{CH}), 7.35-7.28(4 \mathrm{H}, \mathrm{m}, 4 \times \mathrm{CH})$, $7.00(2 \mathrm{H}, \mathrm{t}, J 8.0,2 \times \mathrm{CH}), 6.86(2 \mathrm{H}, \mathrm{dd}, J 7.5,1.3,2 \times \mathrm{CH}), 6.81(2 \mathrm{H}, \mathrm{ddd}, J 8.0,3.0,1.0,2 \times \mathrm{CH}), 4.21(1 \mathrm{H}, \mathrm{d}$, $\left.J 18.3,1 / 2 \times \mathrm{CH}_{2}\right), 4.19\left(1 \mathrm{H}, \mathrm{d}, J 18.3,1 / 2 \times \mathrm{CH}_{2}\right), 3.69\left(1 \mathrm{H}, \mathrm{d}, J 18.3,1 / 2 \times \mathrm{CH}_{2}\right), 3.57\left(1 \mathrm{H}, \mathrm{d}, J 18.3,1 / 2 \times \mathrm{CH}_{2}\right)$, $3.04-2.99\left(4 \mathrm{H}, \mathrm{m}, 2 \times \mathrm{CH}_{2}\right), 2.01-1.95\left(4 \mathrm{H}, \mathrm{m}, 2 \times \mathrm{CH}_{2}\right), 1.73-1.68\left(4 \mathrm{H}, \mathrm{m}, 2 \times \mathrm{CH}_{2}\right), 1.33-1.26(44 \mathrm{H}, \mathrm{m}$, $\left.22 \times \mathrm{CH}_{2}\right), 0.92-0.87\left(12 \mathrm{H}, \mathrm{m}, 4 \times \mathrm{CH}_{3}\right), 4 \times \mathrm{OH}$ not observed; HRMSESIMS m/z: $531.3065[\mathrm{M}+\mathrm{Na}]^{+}(\mathrm{calcd}$ for $\mathrm{C}_{32} \mathrm{H}_{44} \mathrm{O}_{5} \mathrm{Na}, 531.3081$ ); $\mathrm{R}_{\mathrm{f}} 0.19$ (petroleum ether-EtOAc, 4:1).

Paeciloketal B and 1-epi-paeciloketal B (11:14, ( \pm )-1a:1b): ${ }^{1} \mathrm{H}$ and ${ }^{13} \mathrm{C}$ NMR see tables $\mathrm{S} 4-\mathrm{S} 7$. The spectroscopic data was in excellent agreement with the literature, ${ }^{4}$ however the assignments reported for $\mathrm{CH}_{2}-9$ showed discrepancies with the spectra of the natural products. The authors of the isolation paper reported one multiplet resonating at $1.58 \mathrm{ppm}$ for $\mathrm{CH}_{2}-9$ of both $( \pm)-\mathbf{1 a}$ and $( \pm)-\mathbf{1 b}$, so the peak at this position should have integrated to four protons in their spectra, however no integration was shown on the spectrum for this signal. Our synthetic sample showed a multiplet also resonating at $1.58 \mathrm{ppm}$, however it integrated to one proton only (See ${ }^{1} \mathrm{H}$ NMR spectrum (Figure S22) on page S33). Close analysis of the COSY and edited-HSQC spectra of our sample indicated that the $\mathrm{CH}_{2}-9$ of either $( \pm)$-1a or $( \pm)-\mathbf{1 b}$ was split into two signals, resonating at $1.58 \mathrm{ppm}$ and 1.93 ppm (labelled $9^{*}$ ), while the $\mathrm{CH}_{2}-9$ of the other diastereomer resonated at $1.26 \mathrm{ppm}$ and $1.02 \mathrm{ppm}$ (labelled $9^{\dagger}$ ). Close analysis of the edited-HSQC spectrum then led to the subsequent reassignment of several of the ${ }^{13} \mathrm{C}$ signals which are clearly outlined in Tables S6 and S7. See 2D NMR spectra (Figures S24 and S25) on pages S35S36. 


\section{Minimum Inhibitory Concentration Assay Protocol for Yeasts}

Antimicrobial susceptibility of Candida albicans SC5314 (type strain) and Candida utilis SVB-Y1 (clinical isolate subcultured from Auckland City Hospital) was assessed by broth microdilution in accordance with the CLSI recommended protocols. ${ }^{5}$ Briefly, a two-fold dilution series of the test compounds (from $64 \mu \mathrm{M}$ to $0.25 \mu \mathrm{M}$, final) was prepared in triplicate in polypropylene 96-well plates, using RPMI 1640 media (with glutamine and phenol red, without bicarbonate). Inoculum was prepared from a $24 \mathrm{~h}$ old culture by picking 5 colonies $(\sim 1 \mathrm{~mm}$ in diameter) and resuspending these in $0.85 \%$ saline. Upon vortex mixing, the resulting suspension was diluted to provide a solution with absorbance equivalent to that of a 0.5 McFarland standard, approx. 0.1 OD at $530 \mathrm{~nm}$ (using $1 \mathrm{~cm}$ path length cuvette). This suspension was then diluted 1:50 and a further 1:20 with RPMI 1640 media to as to achieve a final inoculum of $0.5 \times 10^{3}$ to $2.5 \times 10^{3} \mathrm{CFU} / \mathrm{mL}$ upon addition to the plate. The plates were incubated at $35{ }^{\circ} \mathrm{C}$ for $48 \mathrm{~h}$ at which time the MIC was determined as the lowest test concentration at which no turbidity was observed across all three replicates. The assay was performed independently on three occasions and the reported MIC defined as the lowest concentration in which agreement was observed for all three biological replicates.

\section{Minimum Inhibitory Concentration Assay Protocol for Moulds}

Antimicrobial susceptibility of Aspergillus fumigatus SVB-F136 (clinical isolate subcultured from Auckland City Hospital) was assessed by broth microdilution in accordance with the CLSI recommended protocols. ${ }^{6}$ Briefly, a two-fold dilution series of the test compounds (from $64 \mu \mathrm{M}$ to $0.25 \mu \mathrm{M}$, final) was prepared in triplicate in polypropylene 96-well plates, using RPMI 1640 media (with glutamine and phenol red, without bicarbonate). Inoculum was prepared from a 7 day culture by harvesting spores with $1 \mathrm{ml}$ of sterile $0.85 \%$ saline and gently scraping the surface with an inoculating loop. After gentle mixing, heavy fragments were allowed to settle for 3 min prior to transferring the upper homogenous suspension to a new tube. The suspension was vortex mixed and the optical density adjusted to 0.1 (using $1 \mathrm{~cm}$ path length cuvette) before diluting 1:50 with RPMI 1640 media to achieve a final inoculum of $0.4 \times 10^{4}$ to $5 \times 10^{4} \mathrm{CFU} / \mathrm{mL}$ upon addition to the plate. The plates were incubated at $35^{\circ} \mathrm{C}$ for $48 \mathrm{~h}$ at which time the MIC was determined as the lowest test concentration at which no turbidity was observed across all three replicates. The assay was performed independently on three occasions and the reported MIC defined as the lowest concentration in which agreement was observed for all three biological replicates.

Table S1: Minimum inhibitory concentration assay results

\begin{tabular}{c|ccc}
\hline \multirow{2}{*}{ Compound } & \multicolumn{3}{|c}{ MIC $(\boldsymbol{\mu M})$} \\
\cline { 2 - 3 } & $\begin{array}{c}\text { C. albicans } \\
(\text { SC5314 })^{\mathrm{T}}\end{array}$ & $\begin{array}{c}\text { C. utilis }(\mathrm{SVB}- \\
\left.\mathrm{Y}^{\mathrm{C}}\right)^{\mathrm{C}}\end{array}$ & $\begin{array}{c}\text { A. fumigatus } \\
(\text { SVB-F136) }\end{array}$ \\
\hline Bysspectin A (2) & $>64$ & $>64$ & $>64$ \\
Paeciloketals $( \pm)-\mathbf{1 a}$ and $( \pm)-\mathbf{1 b}(11: 14$ mixture $)$ & $>64$ & $>64$ & $>64$ \\
\hline
\end{tabular}

$\mathrm{T}=$ type strain ${ }^{\mathrm{C}}=$ clinical isolate 
Table S2. ${ }^{1} \mathrm{H}$ NMR comparison of natural bysspectin A (2) ${ }^{7}$ with synthetic bysspectin A (2).

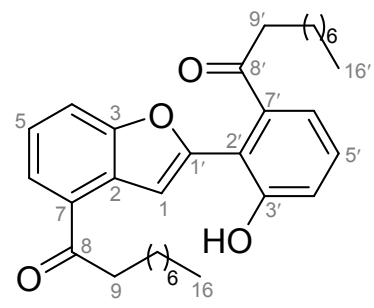

H

Natural 2

Synthetic 2

$\Delta \delta$

$\delta_{\mathrm{H}}\left(600 \mathrm{MHz}, \mathrm{CDCl}_{3}\right)$

$\delta_{\mathrm{H}}\left(500 \mathrm{MHz}, \mathrm{CDCl}_{3}\right)$

\begin{tabular}{|c|c|c|c|}
\hline 1 & $7.83(\mathrm{~d}, J 1.2)$ & $7.85(\mathrm{~d}, J 0.9)$ & +0.02 \\
\hline 4 & $7.66(\mathrm{ddd}, J 7.8,1.2,0.6)$ & $7.66(\mathrm{~d}, J 7.9)$ & 0 \\
\hline 5 & $7.40(\mathrm{t}, J 7.8)$ & $7.39(\mathrm{t}, J 7.9)$ & -0.01 \\
\hline 6 & $7.88(\mathrm{dd}, J 7.8,0.6)$ & $7.87(\mathrm{~d}, J 8.0)$ & -0.01 \\
\hline 9 & $3.07(\mathrm{t}, J 7.2)$ & $3.07(\mathrm{t}, J 7.4)$ & -0.01 \\
\hline 10 & $1.80(\mathrm{~m})$ & 1.79 (pent, $J 7.5$ ) & -0.01 \\
\hline 11 & $1.43(\mathrm{~m})$ & $1.45-1.40(\mathrm{~m})$ & 0 \\
\hline 12 & $1.28-1.39(\mathrm{~m})$ & $1.39-1.19(\mathrm{~m})$ & - a \\
\hline 13 & $1.28-1.39(\mathrm{~m})$ & $1.39-1.19(\mathrm{~m})$ & $-\mathrm{a}$ \\
\hline 14 & $1.17(\mathrm{~m})$ & $1.39-1.19(\mathrm{~m})$ & $-\mathrm{a}$ \\
\hline 15 & $1.25(\mathrm{~m})$ & $1.39-1.19(\mathrm{~m})$ & - a \\
\hline 16 & $0.85(\mathrm{t}, J 7.2)$ & $0.84(\mathrm{t}, J 7.2)$ & -0.01 \\
\hline 3'OH & $6.23(\mathrm{~s})$ & $6.41(\mathrm{~s})$ & +0.18 \\
\hline $4^{\prime}$ & $7.14(\mathrm{dd}, J 7.8,1.2)$ & $7.14(\mathrm{dd}, J 7.9,1.2)$ & 0 \\
\hline $5^{\prime}$ & $7.39(\mathrm{t}, J 7.8)$ & $7.37(\mathrm{t}, J 7.5)$ & -0.02 \\
\hline $6^{\prime}$ & $7.10(\mathrm{dd}, J 7.8,1.2)$ & $7.09(\mathrm{dd}, J 7.3,1.2)$ & -0.01 \\
\hline $9^{\prime}$ & $2.54(\mathrm{t}, J 7.2)$ & $2.54(\mathrm{t}, J 7.4)$ & 0 \\
\hline $10^{\prime}$ & $1.59(\mathrm{~m})$ & 1.59 (pent, $J 7.3$ ) & 0 \\
\hline $11^{\prime}$ & $1.17(\mathrm{~m})$ & $1.39-1.19(\mathrm{~m})$ & - a \\
\hline $12^{\prime}$ & $1.28-1.39(\mathrm{~m})$ & $1.39-1.19(\mathrm{~m})$ & $-\mathrm{a}$ \\
\hline $13^{\prime}$ & $1.28-1.39(\mathrm{~m})$ & $1.39-1.19(\mathrm{~m})$ & $-{ }^{a}$ \\
\hline $14^{\prime}$ & $1.17(\mathrm{~m})$ & $1.39-1.19(\mathrm{~m})$ & $-{ }^{a}$ \\
\hline $15^{\prime}$ & $1.31(\mathrm{~m})$ & $1.39-1.19(\mathrm{~m})$ & $-a$ \\
\hline $16^{\prime}$ & $0.89(\mathrm{t}, J 7.2)$ & $0.88(\mathrm{t}, J 7.0)$ & -0.01 \\
\hline
\end{tabular}

anresolved signals 
Table S3. ${ }^{13} \mathrm{C}$ NMR comparison of natural bysspectin A (2) ${ }^{7}$ with synthetic bysspectin A (2).

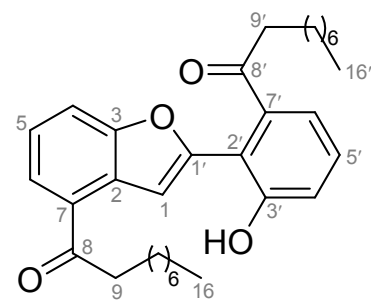

\begin{tabular}{|c|c|c|c|}
\hline C & $\begin{array}{c}\text { Natural 2 } \\
\delta_{\mathrm{C}}\left(150 \mathrm{MHz}, \mathrm{CDCl}_{3}\right)\end{array}$ & $\begin{array}{c}\text { Synthetic 2 } \\
\delta_{\mathrm{C}}\left(125 \mathrm{MHz}, \mathrm{CDCl}_{3}\right)\end{array}$ & $\begin{array}{c}\Delta \delta \\
(1 \mathrm{dp})\end{array}$ \\
\hline 1 & 108.7 & 108.7 & 0 \\
\hline 2 & 128.0 & 128.0 & 0 \\
\hline 3 & 155.6 & 155.6 & 0 \\
\hline 4 & 115.9 & 115.9 & 0 \\
\hline 5 & 124.4 & 124.3 & -0.1 \\
\hline 6 & 125.2 & 125.2 & 0 \\
\hline 7 & 130.3 & 130.2 & -0.1 \\
\hline 8 & 201.0 & 201.1 & +0.1 \\
\hline 9 & 39.5 & 39.5 & 0 \\
\hline 10 & 24.7 & 24.7 & 0 \\
\hline 11 & 29.7 & 29.64 & -0.1 \\
\hline 12 & 29.6 & 29.59 & 0 \\
\hline 13 & 29.5 & 29.4 & -0.1 \\
\hline 14 & 32.0 & 32.0 & 0 \\
\hline 15 & 22.8 & 22.8 & 0 \\
\hline 16 & 14.3 & 14.3 & 0 \\
\hline $1^{\prime}$ & 152.4 & 152.5 & +0.1 \\
\hline $2^{\prime}$ & 114.1 & 114.1 & 0 \\
\hline $3^{\prime}$ & 154.2 & 154.2 & 0 \\
\hline $4^{\prime}$ & 118.7 & 118.7 & 0 \\
\hline $5^{\prime}$ & 131.1 & 131.0 & -0.1 \\
\hline $6^{\prime}$ & 120.0 & 119.9 & -0.1 \\
\hline $7^{\prime}$ & 142.4 & 142.4 & 0 \\
\hline $\mathbf{8}^{\prime}$ & 205.6 & 205.7 & +0.1 \\
\hline $9^{\prime}$ & 42.2 & 42.3 & +0.1 \\
\hline $10^{\prime}$ & 24.5 & 24.5 & 0 \\
\hline $11^{\prime}$ & 29.3 & 29.24 & -0.1 \\
\hline $12^{\prime}$ & 29.3 & 29.21 & -0.1 \\
\hline $13^{\prime}$ & 29.4 & 29.3 & -0.1 \\
\hline $14^{\prime}$ & 31.9 & 31.9 & 0 \\
\hline $15^{\prime}$ & 22.8 & 22.8 & 0 \\
\hline $16^{\prime}$ & 14.2 & 14.2 & 0 \\
\hline
\end{tabular}


Table S4. ${ }^{1} \mathrm{H}$ NMR comparison of natural paeciloketal B $(( \pm)-\mathbf{1 a})^{4}$ with synthetic paeciloketal B $(( \pm)$ 1a).<smiles>CCCCC1(C)O[C@@]2(Cc3c(cccc3C(=O)CC)O2)c2c(O)cccc21</smiles>
H
Natural ( \pm )-1a
Synthetic ( \pm -1a
$\Delta \delta$

$\delta_{\mathrm{H}}\left(500 \mathrm{MHz}\right.$, methanol-d $\left.\mathrm{d}_{4}\right)$

$\delta_{\mathrm{H}}\left(500 \mathrm{MHz}\right.$, methanol- $\left.\mathrm{d}_{4}\right)$

\begin{tabular}{|c|c|c|c|}
\hline 4 & $6.77(\mathrm{~d}, J 8.0)$ & $6.763(\mathrm{~d}, J 7.4)$ & -0.01 \\
\hline 5 & $7.33(\mathrm{t}, J 8.0)$ & $7.36-7.29(\mathrm{~m})$ & $-^{\mathrm{c}}$ \\
\hline 6 & $6.83(\mathrm{~d}, J 8.0)$ & $6.83(\mathrm{~d}, J 8.0)$ & 0 \\
\hline 8 & $1.95(\mathrm{~m})$ & $2.01-1.90(\mathrm{~m})$ & 0 \\
\hline 9 & $1.58(\mathrm{~m})^{\mathrm{d}}$ & $\begin{array}{c}1.58(\mathrm{~m}) \text { and } 1.93(\mathrm{~m}) \text { or } 1.26(\mathrm{~m}) \\
\text { and } 1.02(\mathrm{~m})^{\mathrm{e}}\end{array}$ & $-d$ \\
\hline 10 & $1.24-1.34(\mathrm{~m})$ & $1.39-1.24(\mathrm{~m})$ & $-\mathrm{c}$ \\
\hline 11 & $1.24-1.34(\mathrm{~m})$ & $1.39-1.24(\mathrm{~m})$ & $-\mathrm{c}$ \\
\hline 12 & $1.24-1.34(\mathrm{~m})$ & $1.39-1.24(\mathrm{~m})$ & $-\mathrm{c}$ \\
\hline 13 & n.aca & $1.39-1.24(\mathrm{~m})$ & $-\mathrm{c}$ \\
\hline 14 & n.ac ${ }^{\mathrm{a}}$ & $1.39-1.24(\mathrm{~m})$ & $-^{\mathrm{c}}$ \\
\hline 15 & $0.87(\mathrm{t}, J 7.0)^{\mathrm{b}}$ & $0.87(\mathrm{t}, J 7.1)^{\mathrm{b}}$ & 0 \\
\hline $1^{\prime} \mathbf{a}$ & $4.20(\mathrm{~d}, J 18.0)$ & $4.20(\mathrm{~d}, J 18.3)$ & 0 \\
\hline $1^{\prime} \mathbf{b}$ & $3.73(\mathrm{~d}, J 18.0)$ & $3.73(\mathrm{~d}, J 18.3)$ & 0 \\
\hline $3^{\prime}$ & $7.56(\mathrm{~d}, J 8.0)$ & $7.56(\mathrm{~d}, J 7.9)$ & 0 \\
\hline $4^{\prime}$ & $7.33(\mathrm{t}, J 8.0)$ & $7.36-7.29(\mathrm{~m})$ & $-\mathrm{c}$ \\
\hline $5^{\prime}$ & $6.98(\mathrm{~d}, J 8.0)$ & $6.98(\mathrm{~d}, J 4.9)$ & 0 \\
\hline $7^{\prime}$ & $3.01(\mathrm{t}, J 7.5)$ & $3.013(\mathrm{t}, J 7.3)$ & 0 \\
\hline $8^{\prime}$ & 1.71 (pent, $J 7.0$ ) & 1.70 (pent, $J 7.3$ ) & -0.01 \\
\hline $9^{\prime}$ & $1.24-1.34(\mathrm{~m})$ & $1.39-1.24(\mathrm{~m})$ & $-\mathrm{c}$ \\
\hline $10^{\prime}$ & $1.24-1.34(\mathrm{~m})$ & $1.39-1.24(\mathrm{~m})$ & $-\mathrm{c}$ \\
\hline $11^{\prime}$ & $1.24-1.34(\mathrm{~m})$ & $1.39-1.24(\mathrm{~m})$ & $-\mathrm{c}$ \\
\hline $12^{\prime}$ & $1.24(\mathrm{~m})$ & $1.39-1.24(\mathrm{~m})$ & $-\mathrm{c}$ \\
\hline $13^{\prime}$ & $1.26(\mathrm{~m})$ & $1.39-1.24(\mathrm{~m})$ & $-\mathrm{c}$ \\
\hline $14^{\prime}$ & $0.89(\mathrm{t}, J 7.0)^{\mathrm{b}}$ & $0.89(\mathrm{t}, J 6.9)^{\mathrm{b}}$ & 0 \\
\hline$-\mathrm{OCH}_{3}$ & $2.98(\mathrm{~s})$ & $2.98(\mathrm{~s})$ & 0 \\
\hline
\end{tabular}

${ }^{a}$ Not assigned; bassignments with the same superscript in the same column may be interchanged; ${ }^{\circ}$ Unresolved signals; ${ }^{\mathrm{d}}$ Signal missassigned in the isolation report, refer to discussion on page S4 and 2D NMR spectra on pages S35-S36 for details; ${ }^{\mathrm{e}}$ Could not unequivocally assign diastereotopic signals. 
Table S5. ${ }^{1} \mathrm{H}$ NMR comparison of natural 1-epi-paeciloketal B $(( \pm)-1 \mathbf{b})^{4}$ with synthetic 1-epipaeciloketal B (((土)-1b).

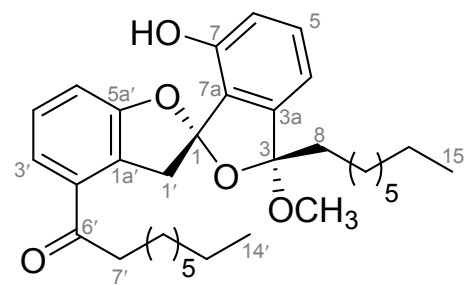

\section{H}

$$
\text { Natural ( } \pm \text { )-1b }
$$

Synthetic ( \pm )-1b

$\Delta \delta$ $\delta_{\mathrm{H}}\left(500 \mathrm{MHz}\right.$, methanol-d $\left._{4}\right)$

$\delta_{\mathrm{H}}\left(500 \mathrm{MHz}\right.$, methanol-d $\left.\mathrm{d}_{4}\right)$

\begin{tabular}{|c|c|c|c|}
\hline 4 & $6.76(\mathrm{~d}, J 8.0)$ & $6.759(\mathrm{~d}, J 7.5)$ & 0 \\
\hline 5 & $7.34(\mathrm{t}, J 8.0)$ & $7.36-7.29(\mathrm{~m})$ & $-\mathrm{c}$ \\
\hline 6 & $6.82(\mathrm{~d}, J 8.0)$ & $6.82(\mathrm{~d}, J 8.0)$ & 0 \\
\hline 8 & $1.96(\mathrm{~m})$ & $2.01-1.90(\mathrm{~m})$ & -0.01 \\
\hline 9 & $1.58(\mathrm{~m})^{\mathrm{d}}$ & $\begin{array}{c}1.58(\mathrm{~m}) \text { and } 1.93(\mathrm{~m}) \text { or } 1.26(\mathrm{~m}) \\
\text { and } 1.02(\mathrm{~m})^{\mathrm{e}}\end{array}$ & $-{ }^{d}$ \\
\hline 10 & $1.24-1.34(\mathrm{~m})$ & $1.39-1.24(\mathrm{~m})$ & $--^{c}$ \\
\hline 11 & $1.24-1.34(\mathrm{~m})$ & $1.39-1.24(\mathrm{~m})$ & $-\mathrm{c}$ \\
\hline 12 & $1.24-1.34(\mathrm{~m})$ & $1.39-1.24(\mathrm{~m})$ & $-\mathrm{c}$ \\
\hline 13 & $\mathrm{n} \cdot \mathrm{ac}^{\mathrm{a}}$ & $1.39-1.24(\mathrm{~m})$ & $-\mathrm{c}$ \\
\hline 14 & n. $\mathrm{ac}^{\mathrm{a}}$ & $1.39-1.24(\mathrm{~m})$ & $-\mathrm{c}$ \\
\hline 15 & $0.87(\mathrm{t}, J 7.0)^{\mathrm{b}}$ & $0.87(\mathrm{t}, J 7.1)^{\mathrm{b}}$ & 0 \\
\hline $1^{\prime} \mathbf{a}$ & $4.13(\mathrm{~d}, J 18.0)$ & $4.13(\mathrm{~d}, J 18.2)$ & 0 \\
\hline $\mathbf{1}^{\prime} \mathbf{b}$ & $3.60(\mathrm{~d}, J 18.0)$ & $3.60(\mathrm{~d}, J 18.2)$ & 0 \\
\hline $3^{\prime}$ & $7.55(\mathrm{~d}, J 8.0)$ & $7.55(\mathrm{~d}, J 7.8)$ & 0 \\
\hline $4^{\prime}$ & $7.34(\mathrm{t}, J 8.0)$ & $7.36-7.29(\mathrm{~m})$ & $-\mathrm{c}$ \\
\hline $5^{\prime}$ & $7.01(\mathrm{~d}, J 8.0)$ & $7.01(\mathrm{~d}, J 7.9)$ & 0 \\
\hline $7^{\prime}$ & $3.02(\mathrm{t}, J 7.5)$ & $3.009(\mathrm{t}, J 7.4)$ & -0.01 \\
\hline $8^{\prime}$ & 1.71 (pent, $J 7.0$ ) & 1.70 (pent, $J 7.3$ ) & -0.01 \\
\hline $9^{\prime}$ & $1.24-1.34(\mathrm{~m})$ & $1.39-1.24(\mathrm{~m})$ & $-\mathrm{c}$ \\
\hline $10^{\prime}$ & $1.24-1.34(\mathrm{~m})$ & $1.39-1.24(\mathrm{~m})$ & $-\mathrm{c}$ \\
\hline $11^{\prime}$ & $1.24-1.34(\mathrm{~m})$ & $1.39-1.24(\mathrm{~m})$ & $-c$ \\
\hline $12^{\prime}$ & $1.24(\mathrm{~m})$ & $1.39-1.24(\mathrm{~m})$ & $-{ }^{c}$ \\
\hline $13^{\prime}$ & $1.26(\mathrm{~m})$ & $1.39-1.24(\mathrm{~m})$ & $--^{c}$ \\
\hline $14^{\prime}$ & $0.89(\mathrm{t}, J 7.0)^{\mathrm{b}}$ & $0.89(\mathrm{t}, J 6.9)^{\mathrm{b}}$ & 0 \\
\hline$-\mathrm{OCH}_{3}$ & $3.12(\mathrm{~s})$ & $3.12(\mathrm{~s})$ & 0 \\
\hline
\end{tabular}

aNot assigned; bassignments with the same superscript in the same column may be interchanged; ' Unresolved signals; ${ }^{\mathrm{d}}$ Signal missassigned in the isolation report, refer to discussion on page S4 and 2D NMR spectra on pages S35-S36 for details; ${ }^{\mathrm{e}}$ Could not unequivocally assign diastereotopic signals. 
Table S6. ${ }^{13} \mathrm{C}$ NMR comparison of natural paeciloketal B $\left.(( \pm)-1 \mathbf{a})\right)^{4}$ with synthetic paeciloketal B $(( \pm)$ 1a).

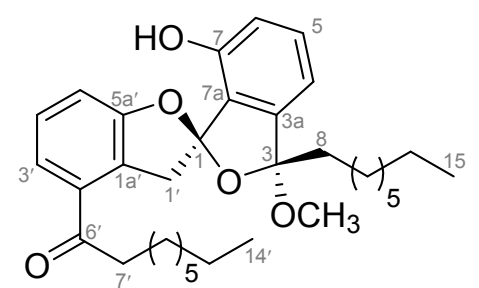

\begin{tabular}{|c|c|c|c|c|}
\hline $\mathbf{C}$ & $\begin{array}{c}\text { Natural }( \pm)-\mathbf{1 a} \\
\delta_{\mathrm{C}}\left(100 \mathrm{MHz}, \text { methanol-d } \mathrm{d}_{4}\right)\end{array}$ & $\begin{array}{c}\text { Synthetic }( \pm)-\mathbf{1 a} \\
\delta_{\mathrm{C}}\left(125 \mathrm{MHz}, \text { methanol-d } \mathrm{d}_{4}\right)\end{array}$ & $\begin{array}{c}\Delta \delta \\
(1 \mathrm{dp})\end{array}$ & $\begin{array}{l}\text { Synthetic }( \pm)-1 \text { a } \text { reassigned }^{\text {a }} \\
\delta_{\mathrm{C}}\left(125 \mathrm{MHz} \text {, methanol- } \mathrm{d}_{4}\right)\end{array}$ \\
\hline 1 & 116.9 & 116.9 & 0 & - \\
\hline 3 & 114.2 & 114.2 & 0 & - \\
\hline $3 \mathbf{a}$ & 141.8 & 141.9 & +0.1 & - \\
\hline 4 & 112.7 & 112.7 & 0 & - \\
\hline 5 & 131.8 & 131.9 & +0.1 & - \\
\hline 6 & 115.9 & 115.9 & 0 & - \\
\hline 7 & 153.5 & 153.6 & +0.1 & - \\
\hline $7 \mathbf{a}$ & 125.9 & 125.9 & 0 & - \\
\hline 8 & 39.3 & 39.3 & 0 & 40.0 \\
\hline 9 & 23.2 & 23.2 & 0 & $23.6 / 23.2^{b}$ \\
\hline 10 & $29.1-29.6$ & $29.0-29.6$ & 0 & - \\
\hline 11 & $29.1-29.6$ & $29.0-29.6$ & 0 & - \\
\hline 12 & $29.1-29.6$ & $29.0-29.6$ & 0 & - \\
\hline 13 & 31.8 & 31.8 & 0 & - \\
\hline 14 & 23.6 & 23.6 & 0 & 22.5 \\
\hline 15 & 13.2 & 13.2 & 0 & - \\
\hline $1^{\prime}$ & 40.4 & 40.3 & -0.1 & - \\
\hline $1 a^{\prime}$ & 127.1 & 127.1 & 0 & - \\
\hline $2^{\prime}$ & 133.6 & 133.6 & 0 & - \\
\hline $3^{\prime}$ & 121.3 & 121.4 & +0.1 & - \\
\hline $4^{\prime}$ & 128.0 & 128.0 & 0 & - \\
\hline $5^{\prime}$ & 113.1 & 113.1 & 0 & - \\
\hline $5 \mathbf{a}^{\prime}$ & 159.5 & 159.5 & 0 & - \\
\hline $6^{\prime}$ & 202.4 & 202.4 & 0 & - \\
\hline $7^{\prime}$ & 40.0 & 40.0 & 0 & 39.3 \\
\hline $8^{\prime}$ & 24.4 & 24.4 & 0 & - \\
\hline $9^{\prime}$ & $29.1-29.6$ & $29.0-29.6$ & 0 & - \\
\hline $10^{\prime}$ & $29.1-29.6$ & $29.0-29.6$ & 0 & - \\
\hline $11^{\prime}$ & $29.1-29.6$ & $29.0-29.6$ & 0 & - \\
\hline $12^{\prime}$ & 31.8 & 31.8 & 0 & - \\
\hline $13^{\prime}$ & 22.5 & 22.5 & 0 & 22.5 \\
\hline $14^{\prime}$ & 13.2 & 13.2 & 0 & - \\
\hline 3-OCH & 49.5 & 49.5 & 0 & - \\
\hline
\end{tabular}

${ }^{a}$ Reassignments based on 2D NMR spectra, see pages S35-S36; b Could not distinguish diastereotopic signals 
Table S7. ${ }^{13} \mathrm{C}$ NMR comparison of natural 1-epi-paeciloketal B $(( \pm)-\mathbf{1 b})^{4}$ with synthetic 1-epipaeciloketal B $(( \pm)-\mathbf{1 b})$.

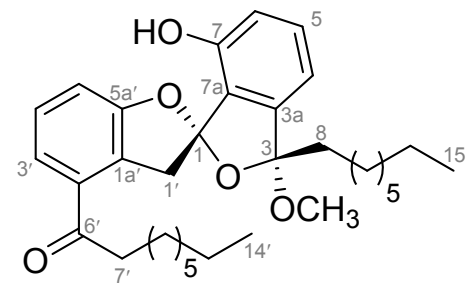
C
Natural ( \pm -1 $\mathbf{1 b}$
Synthetic $( \pm)-\mathbf{1 b}$
$\Delta \delta \quad$ Synthetic $( \pm)-\mathbf{1 b}$ reassigned ${ }^{\mathrm{a}}$
$\delta_{\mathrm{C}}\left(100 \mathrm{MHz}\right.$, methanol- $\left.\mathrm{d}_{4}\right)$
$\delta_{\mathrm{C}}\left(125 \mathrm{MHz}\right.$, methanol-d $\left._{4}\right) \quad(1 \mathrm{dp})$
$\delta_{\mathrm{C}}\left(125 \mathrm{MHz}\right.$, methanol-d $\left.\mathrm{d}_{4}\right)$

\begin{tabular}{|c|c|c|c|c|}
\hline 1 & 116.1 & 116.1 & 0 & - \\
\hline 3 & 113.3 & 113.4 & +0.1 & - \\
\hline $3 a$ & 141.1 & 141.1 & 0 & - \\
\hline 4 & 112.6 & 112.6 & 0 & - \\
\hline 5 & 132.0 & 132.0 & 0 & - \\
\hline 6 & 115.9 & 115.9 & 0 & - \\
\hline 7 & 153.5 & 153.6 & +0.1 & - \\
\hline $7 a$ & 126.0 & 126.0 & 0 & - \\
\hline 8 & 39.3 & 39.3 & 0 & 40.0 \\
\hline 9 & 23.2 & 23.2 & 0 & $23.6 / 23.2^{b}$ \\
\hline 10 & $29.1-29.6$ & $29.0-29.6$ & 0 & - \\
\hline 11 & $29.1-29.6$ & $29.0-29.6$ & 0 & - \\
\hline 12 & $29.1-29.6$ & $29.0-29.6$ & 0 & - \\
\hline 13 & 31.8 & 31.8 & 0 & - \\
\hline 14 & 23.6 & 23.6 & 0 & 22.5 \\
\hline 15 & 13.2 & 13.2 & 0 & - \\
\hline $1^{\prime}$ & 40.9 & 40.9 & 0 & - \\
\hline $1 a^{\prime}$ & 127.1 & 127.1 & 0 & - \\
\hline $2^{\prime}$ & 133.6 & 133.6 & 0 & - \\
\hline $3^{\prime}$ & 121.5 & 121.5 & 0 & - \\
\hline $4^{\prime}$ & 128.0 & 128.0 & 0 & - \\
\hline $5^{\prime}$ & 113.1 & 113.1 & 0 & - \\
\hline $5 a^{\prime}$ & 159.4 & 159.4 & 0 & - \\
\hline $6^{\prime}$ & 202.4 & 202.4 & 0 & - \\
\hline $7^{\prime}$ & 40.0 & 40.0 & 0 & 39.3 \\
\hline $8^{\prime}$ & 24.4 & 24.4 & 0 & - \\
\hline $9^{\prime}$ & $29.1-29.6$ & $29.0-29.6$ & 0 & - \\
\hline $10^{\prime}$ & $29.1-29.6$ & $29.0-29.6$ & 0 & - \\
\hline $11^{\prime}$ & $29.1-29.6$ & $29.0-29.6$ & 0 & - \\
\hline $12^{\prime}$ & 31.8 & 31.8 & 0 & - \\
\hline $13^{\prime}$ & 22.5 & 22.5 & 0 & 22.5 \\
\hline $14^{\prime}$ & 13.2 & 13.2 & 0 & - \\
\hline $3-\mathrm{OCH}_{3}$ & 49.9 & 50.0 & +0.1 & - \\
\hline
\end{tabular}

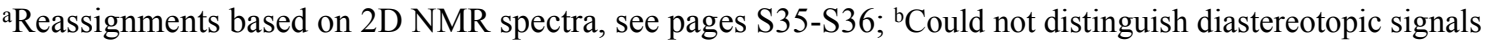




\section{References}

(1) Piers, E.; Harrison, C. L.; Zetina-Rocha, C. Org. Lett. 2001, 3, 3245-3247.

(2) Mori, K.; Ichikawa, Y.; Kobayashi, M.; Shibata, Y.; Yamanaka, M.; Akiyama, T. J. Am. Chem. Soc. 2013, 135, 3964-3970.

(3) Yang, F.; Liu, X.; Shi, X.; Wang, Y.; Hu, G.; Lin, S.; Jiao, X.; Xie, P. Tetrahedron 2019, 75, 3101-3107.

(4) Wang, H.; Hong, J.; Yin, J.; Moon, H. R.; Liu, Y.; Wei, X.; Oh, D.-C.; Jung, J. H. J. Nat. Prod. 2015, 78, 2832-2836.

(5) National Committee for Clinical Laboratory Standards. 2002. Reference method for broth dilution antifungal susceptibility testing of yeasts. Approved standard-second edition M27-A2, Vol. 22 No. 15. National Committee for Clinical Laboratory Standards, Wayne, Pa.

(6) National Committee for Clinical Laboratory Standards. 2002. Reference Method for Broth Dilution Antifungal Susceptibility Testing of Filamentous Fungi. Approved standard-second edition M38-A, Vol. 22 No. 16. National Committee for Clinical Laboratory Standards, Wayne, Pa.

(7) Wu, Y.-Z.; Zhang, H.-W.; Sun, Z.-H.; Dai, J.-G.; Hu, Y.-C.; Li, R.; Lin, P.-C.; Xia, G.-Y.; Wang, L.-Y.; Qiu, B.-L.; Zhang, J.-F.; Ge, G.-B.; Lin, S. Eur. J. Med. Chem. 2018, 145, 717-725. 


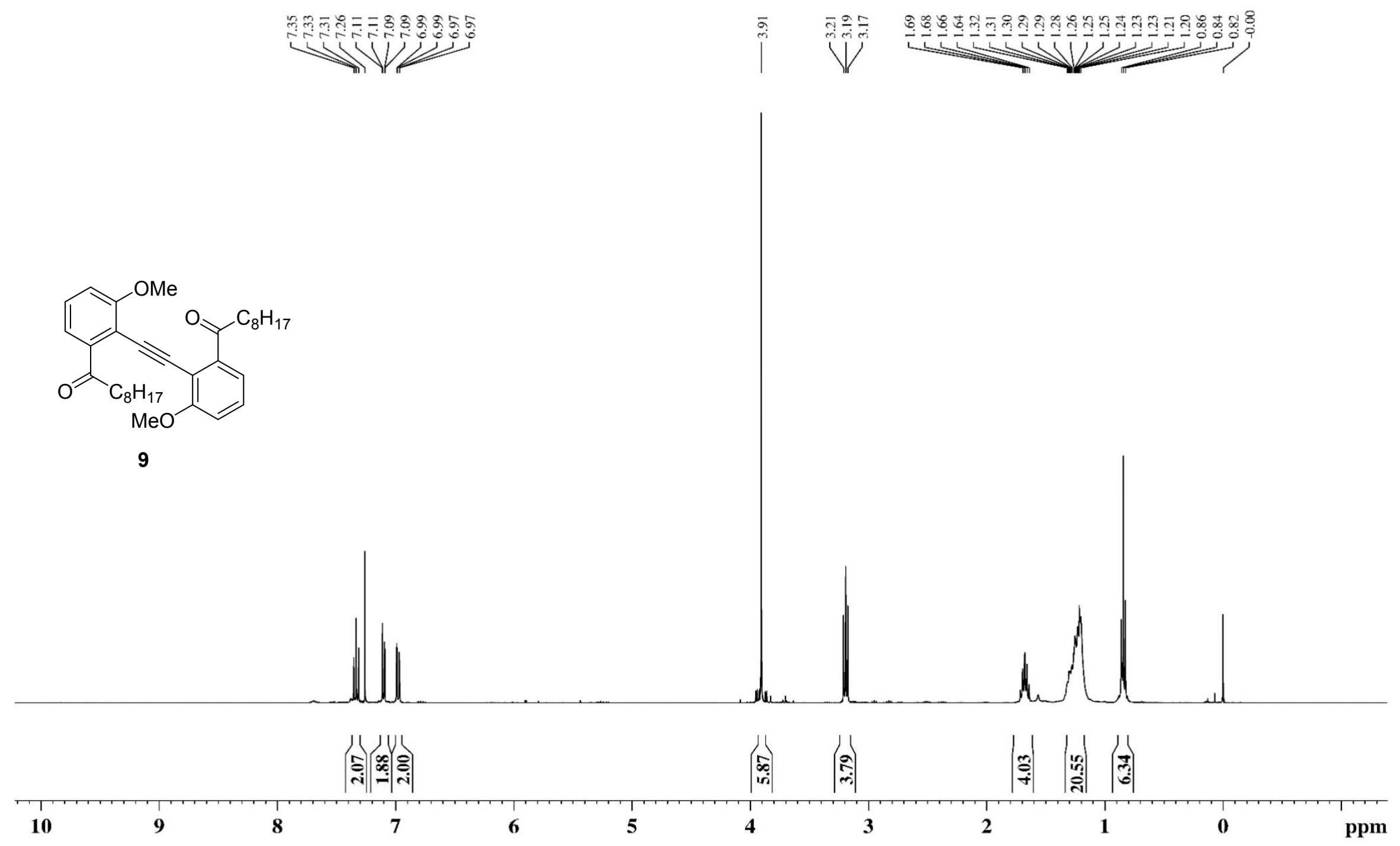

Figure S1. ${ }^{1} \mathrm{H}$ NMR spectrum $\left(400 \mathrm{MHz}, \mathrm{CDCl}_{3}\right)$ of compound 9 

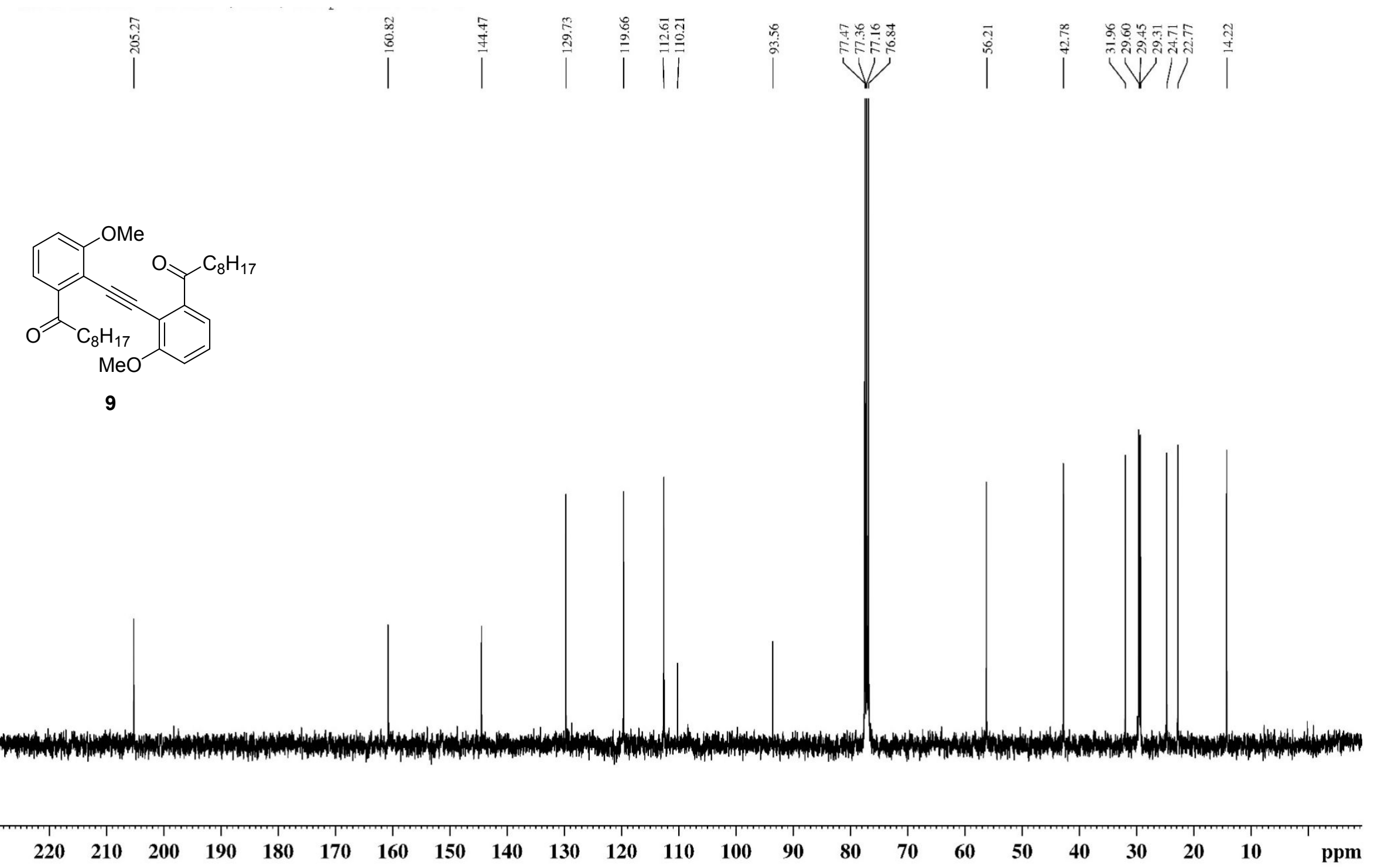

Figure S2. ${ }^{13} \mathrm{C}$ NMR spectrum $\left(100 \mathrm{MHz}, \mathrm{CDCl}_{3}\right)$ of compound 9 


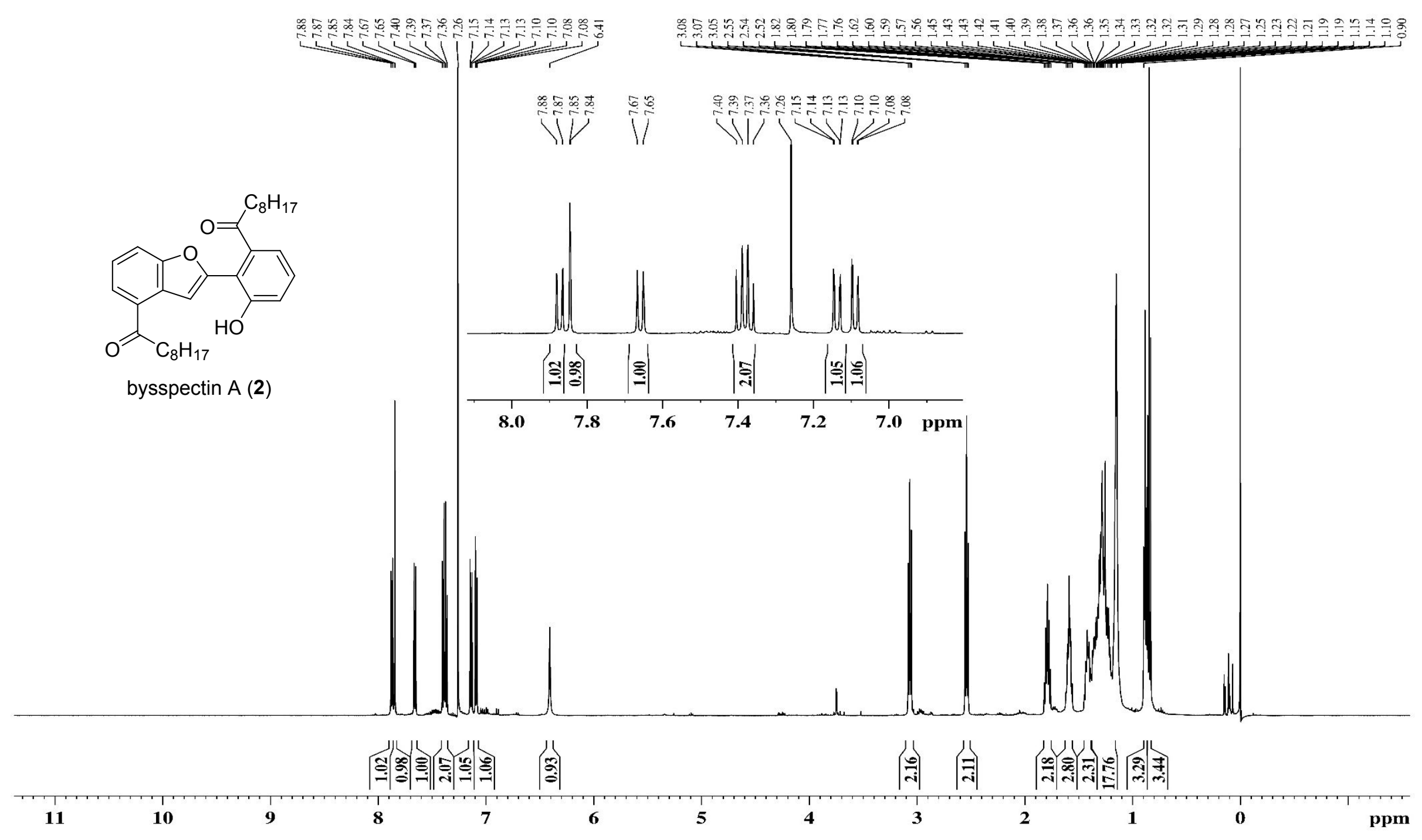

Figure S3. ${ }^{1} \mathrm{H}$ NMR spectrum $\left(500 \mathrm{MHz}, \mathrm{CDCl}_{3}\right)$ of bysspectin A (2) 


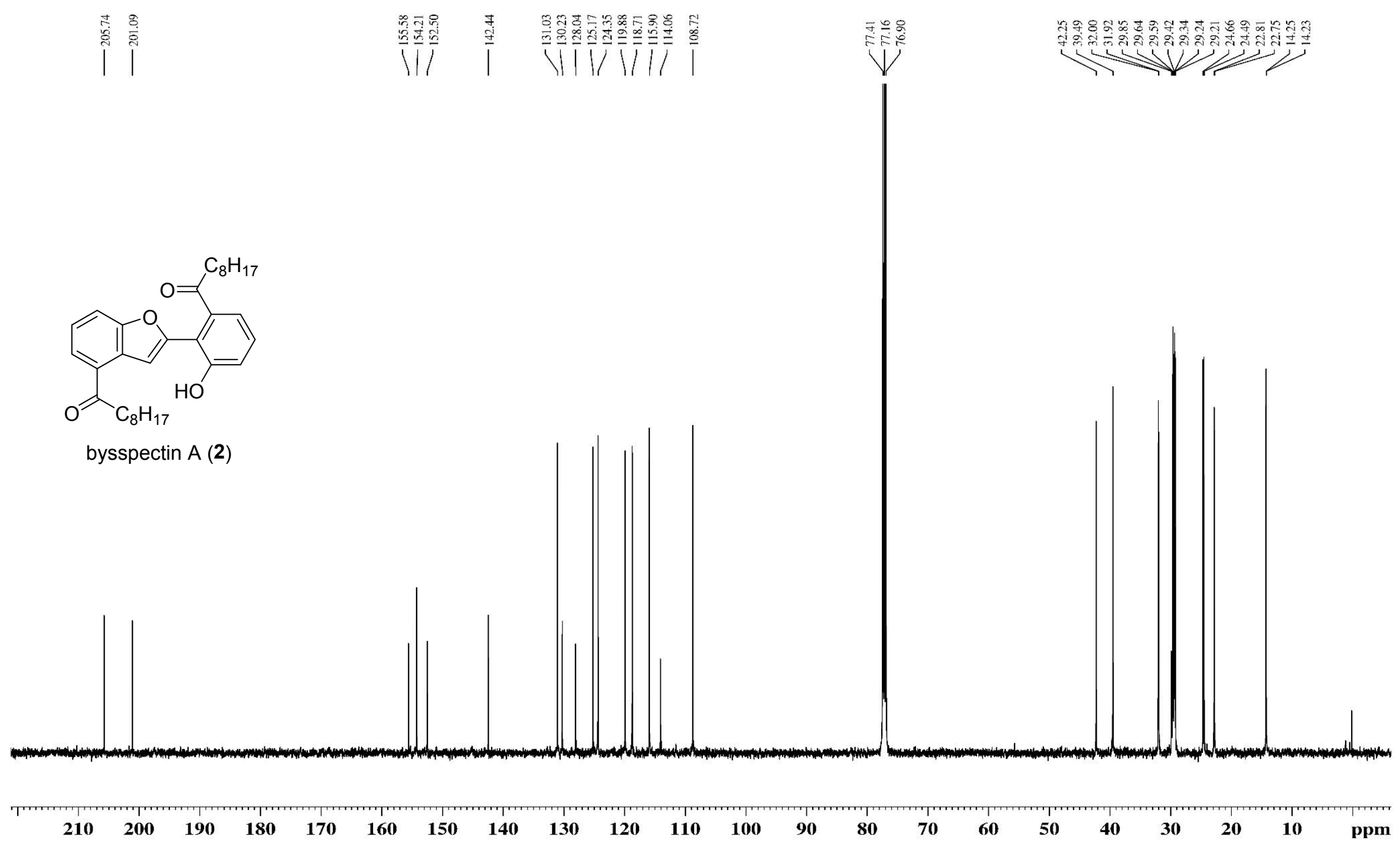

Figure S4. ${ }^{13} \mathrm{C}$ NMR spectrum (125 MHz, $\mathrm{CDCl}_{3}$ ) of bysspectin $\mathrm{A}(2)$ 


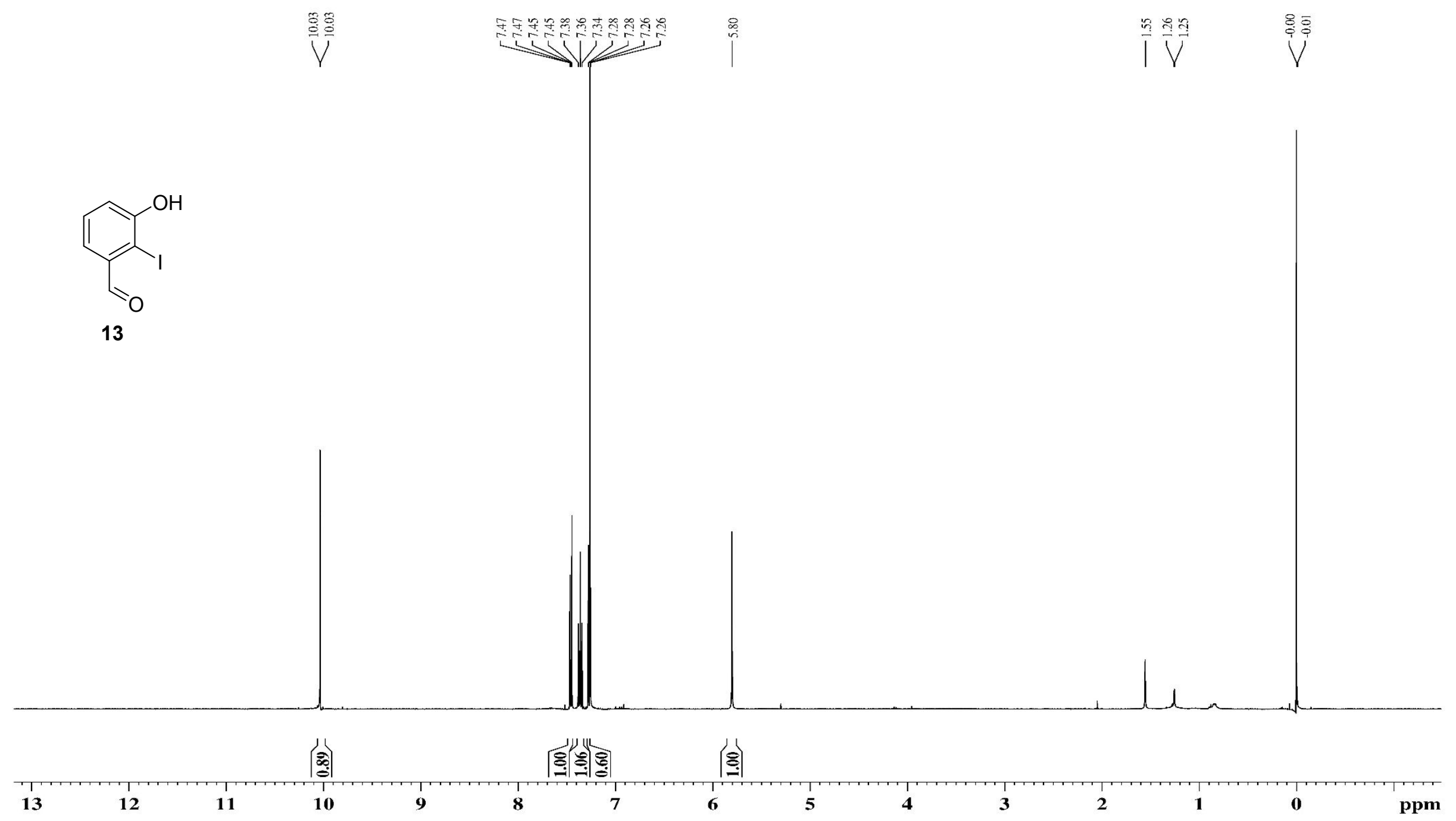

Figure S5. ${ }^{1} \mathrm{H}$ NMR spectrum $\left(400 \mathrm{MHz}, \mathrm{CDCl}_{3}\right)$ of compound $\mathbf{1 3}$ 


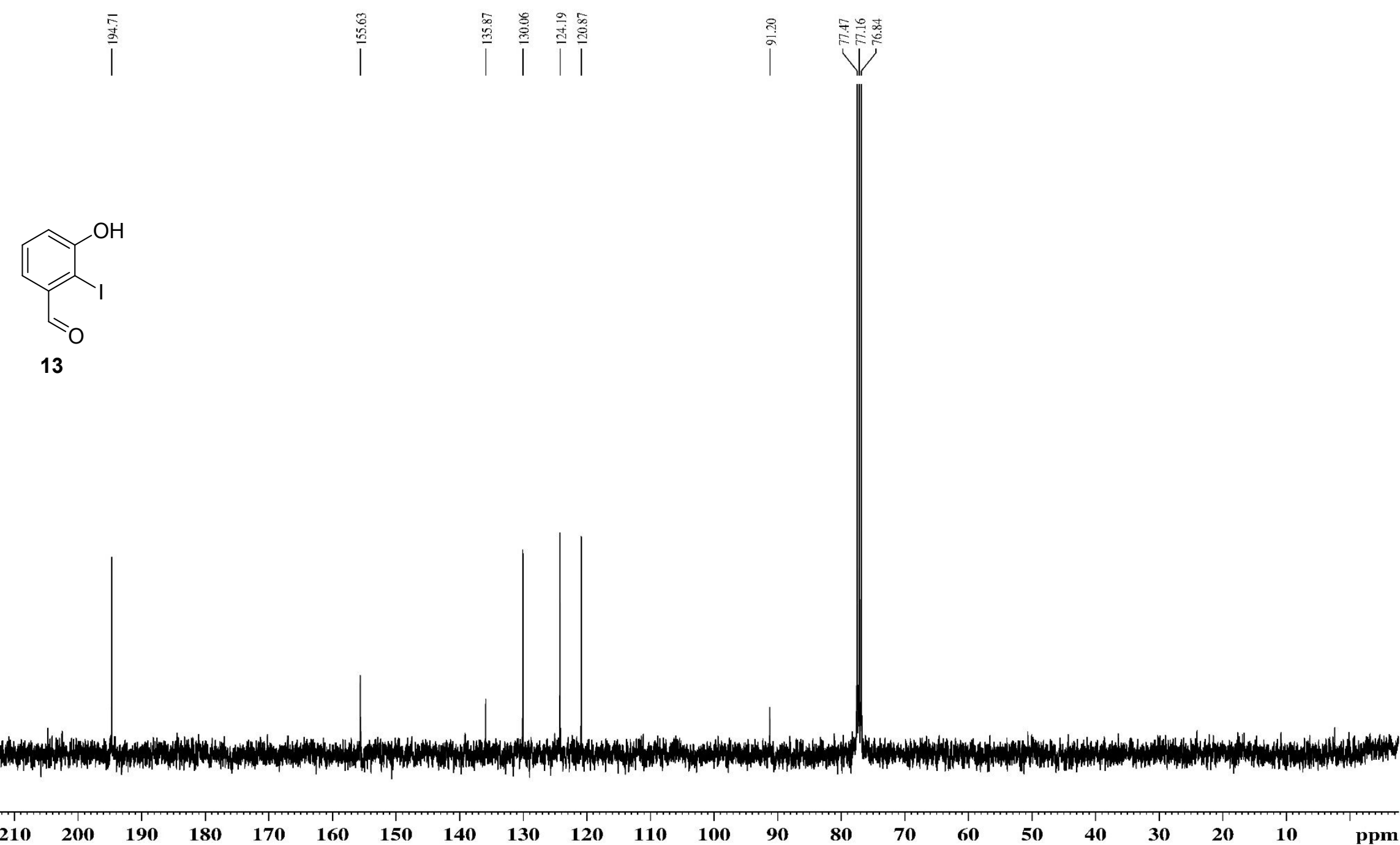

Figure S6. ${ }^{13} \mathrm{C}$ NMR spectrum $\left(100 \mathrm{MHz}, \mathrm{CDCl}_{3}\right)$ of compound 13 


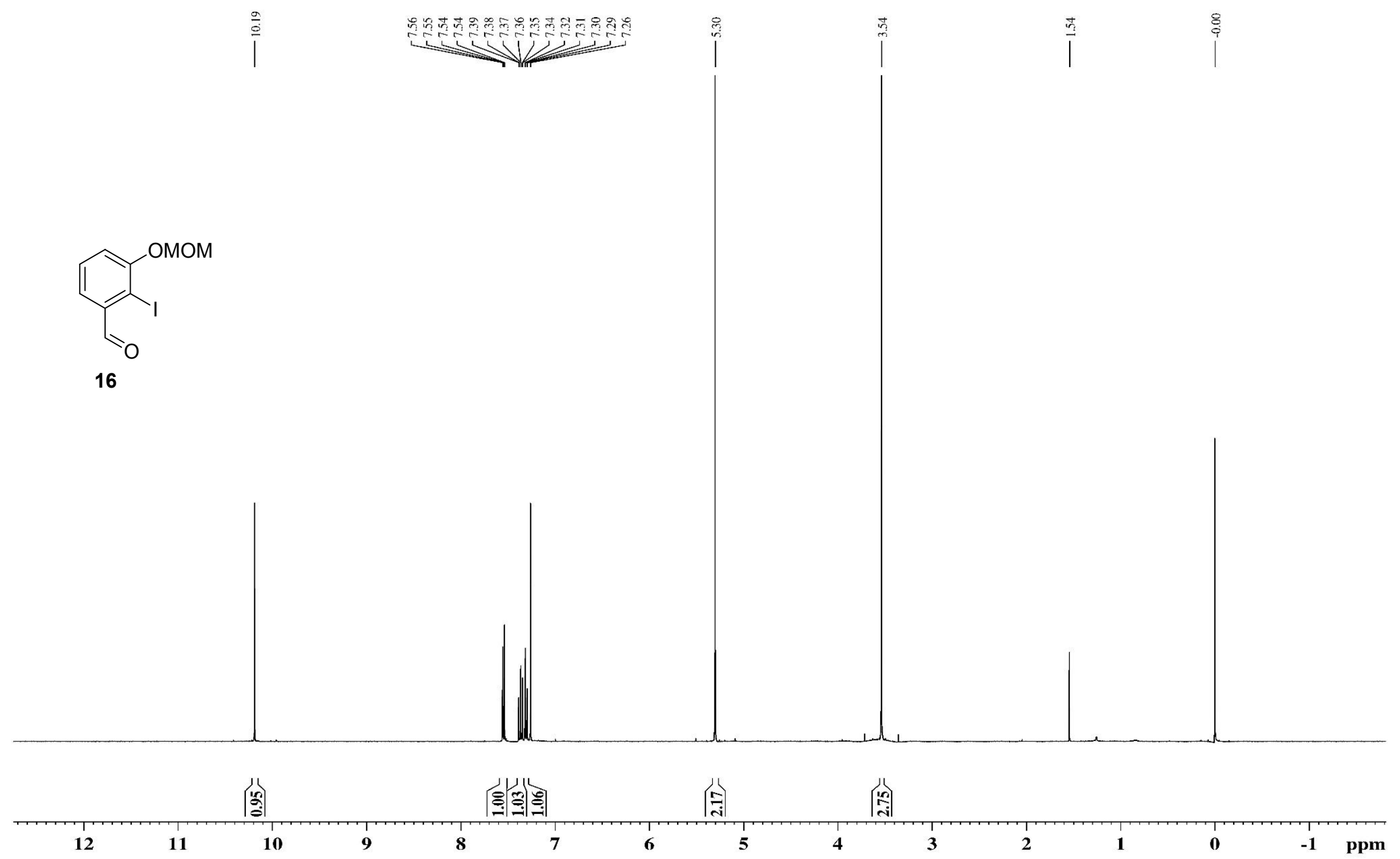

Figure S7. ${ }^{1} \mathrm{H}$ NMR spectrum $\left(400 \mathrm{MHz}, \mathrm{CDCl}_{3}\right)$ of compound $\mathbf{1 6}$ 

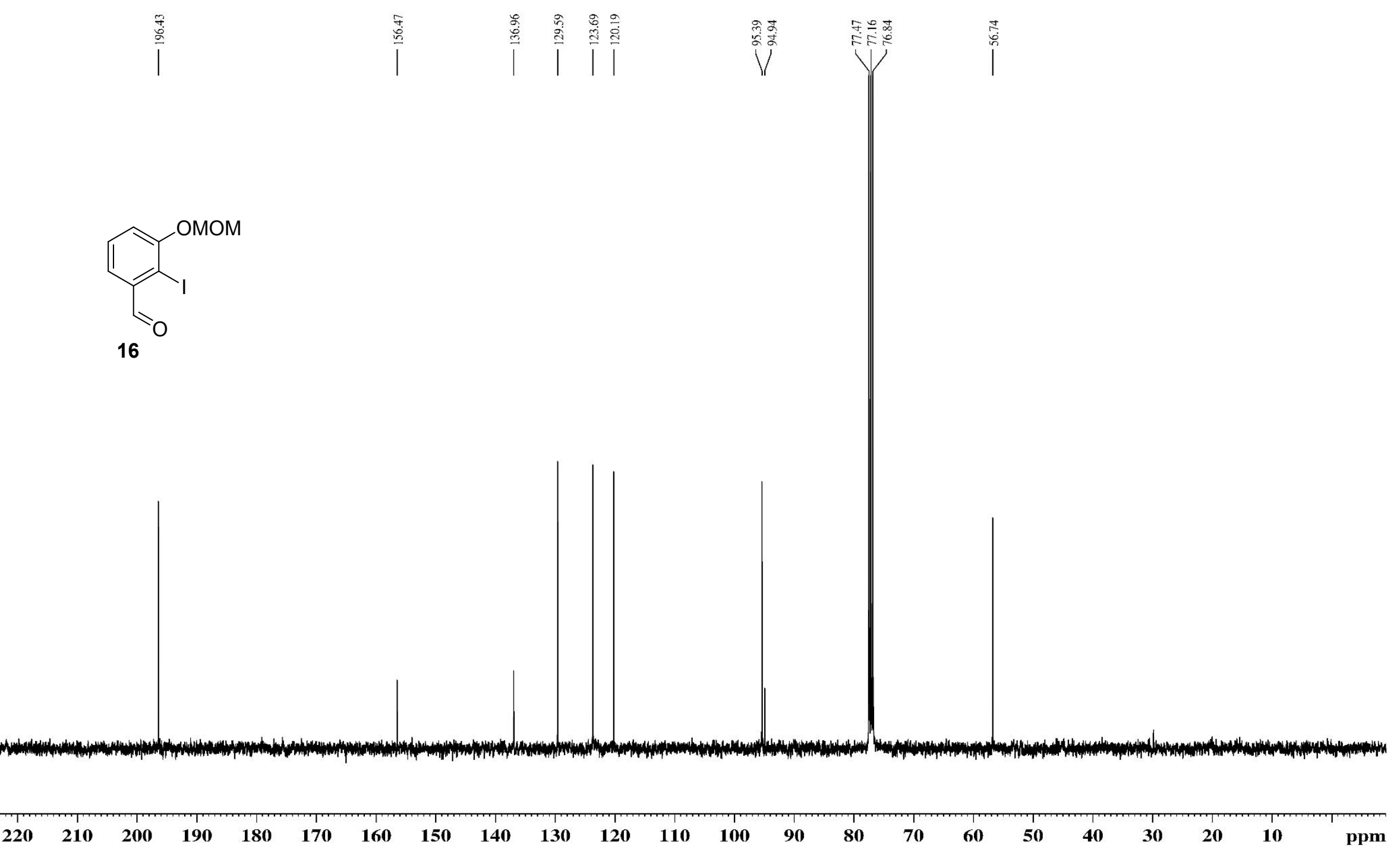

Figure S8. ${ }^{13} \mathrm{C}$ NMR spectrum $\left(100 \mathrm{MHz}, \mathrm{CDCl}_{3}\right)$ of compound $\mathbf{1 6}$ 


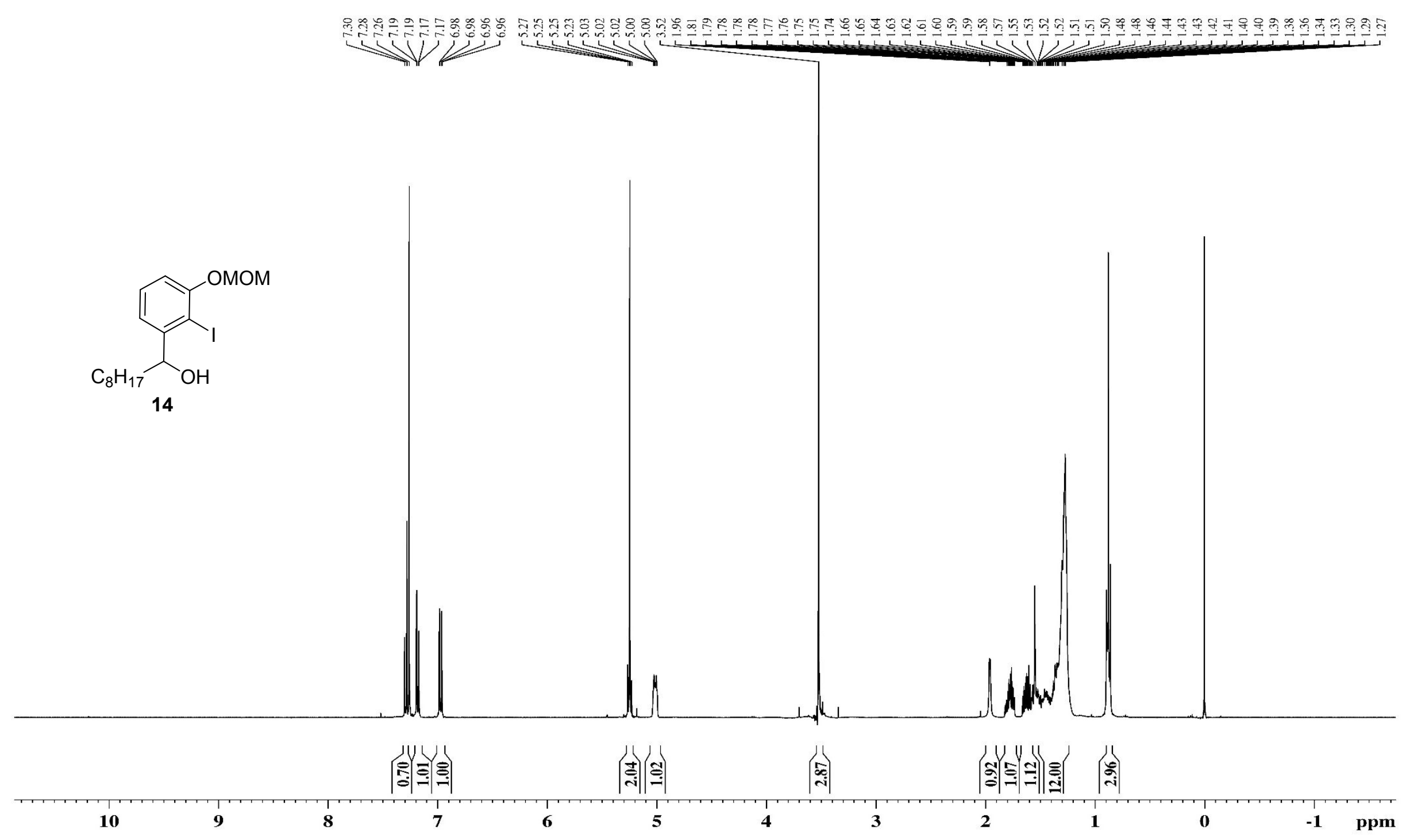

Figure S9. ${ }^{1} \mathrm{H}$ NMR spectrum $\left(400 \mathrm{MHz}, \mathrm{CDCl}_{3}\right)$ of compound 14 


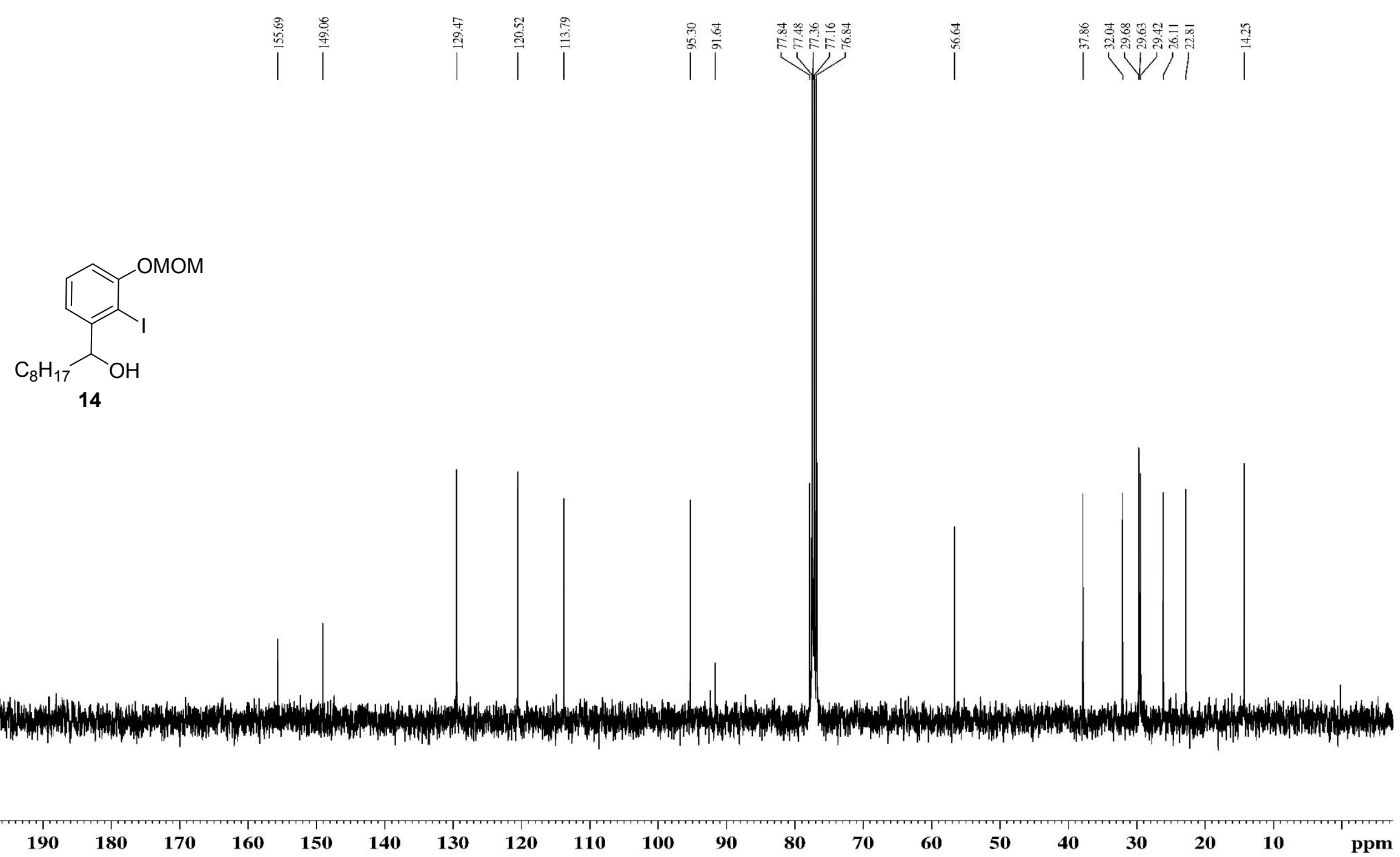

$\begin{array}{lllllllllllllllllllllllllll}200 & 190 & 180 & 170 & 160 & 150 & 140 & 130 & 120 & 110 & 100 & 90 & 80 & 70 & 60 & 50 & 40 & 30 & 20 & 10 & \text { ppm }\end{array}$

Figure S10. ${ }^{13} \mathrm{C}$ NMR spectrum $\left(100 \mathrm{MHz}, \mathrm{CDCl}_{3}\right)$ of compound 14 


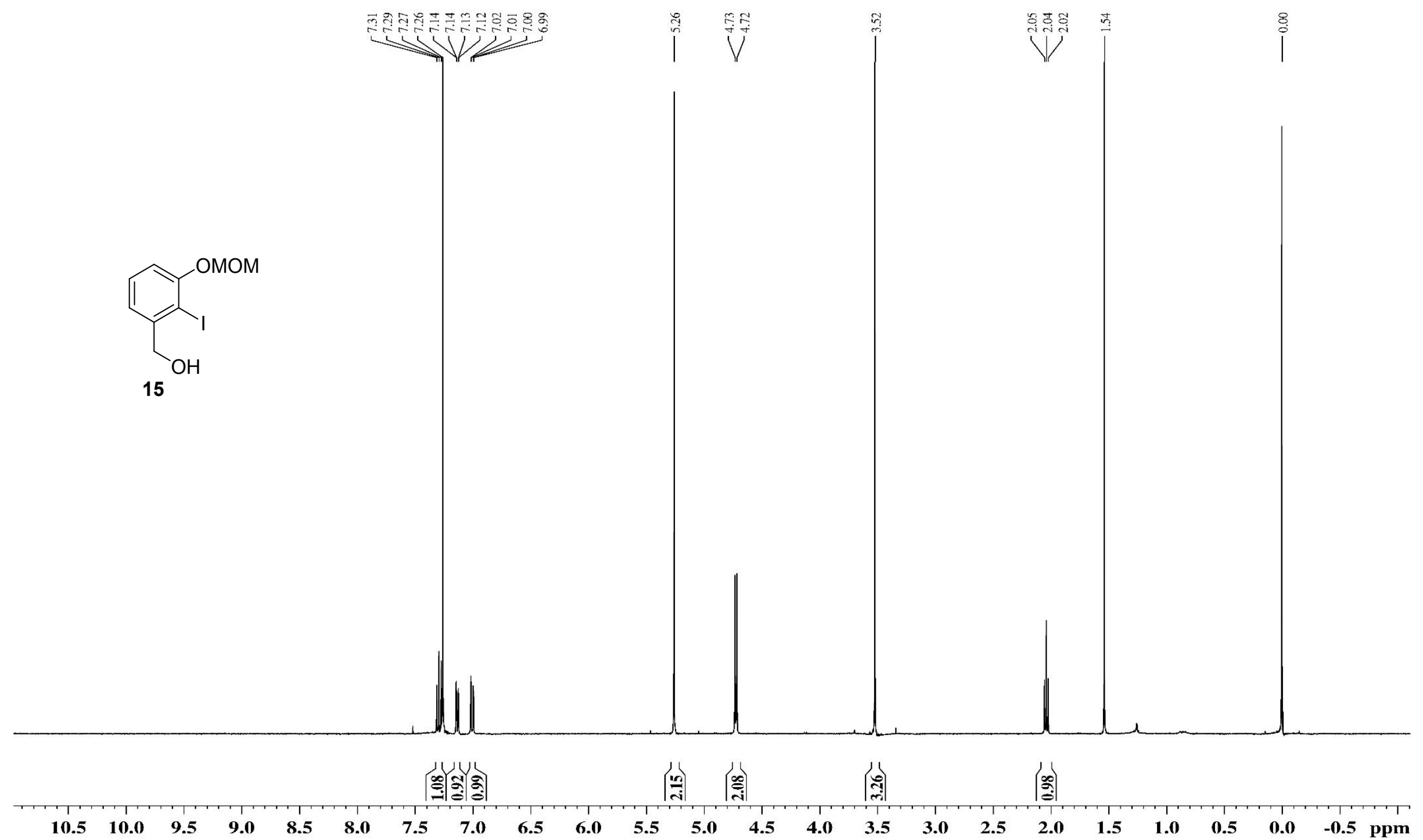

Figure S11. ${ }^{1} \mathrm{H}$ NMR spectrum $\left(400 \mathrm{MHz}, \mathrm{CDCl}_{3}\right)$ of compound 15 


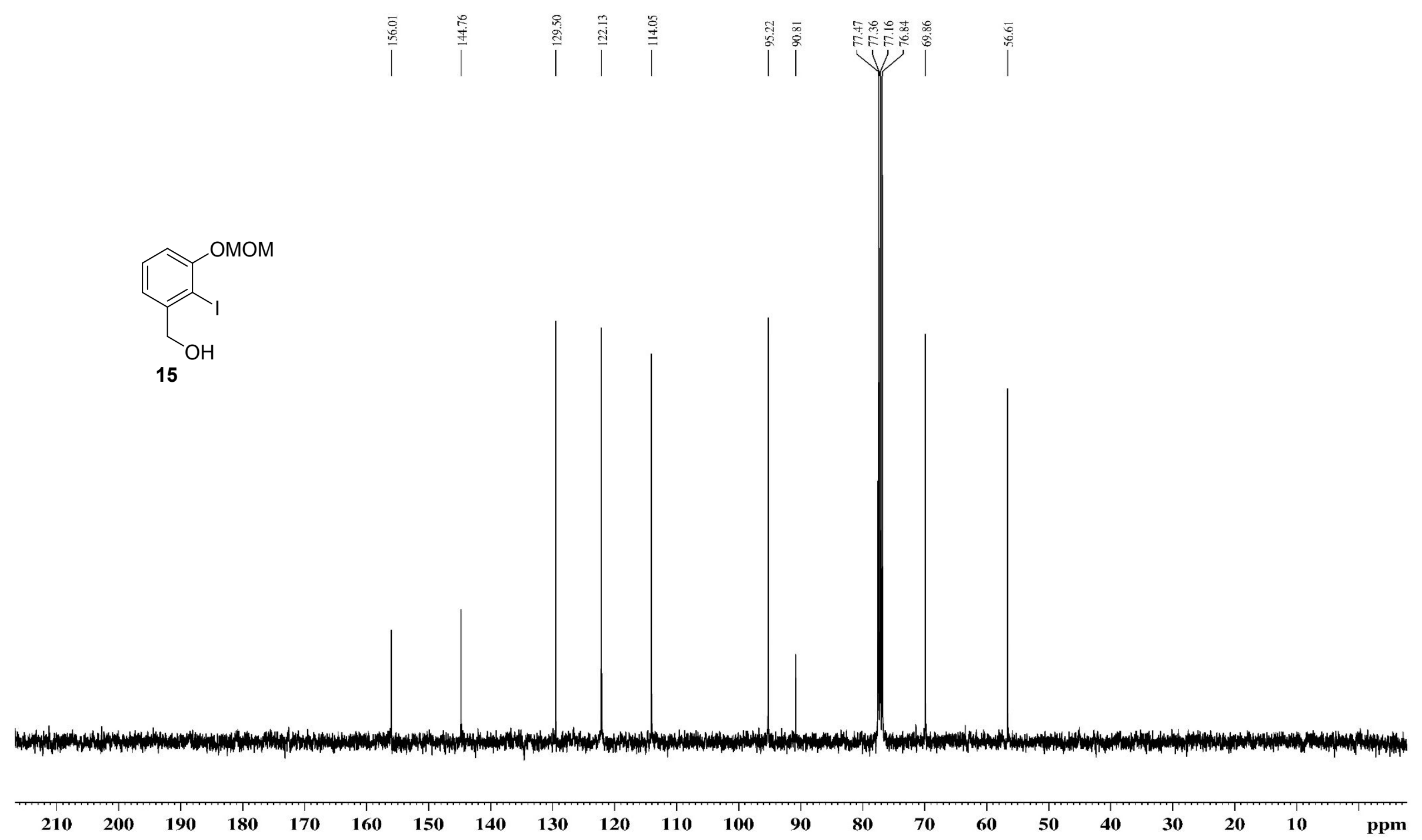

Figure S12. ${ }^{13} \mathrm{C}$ NMR spectrum $\left(100 \mathrm{MHz}, \mathrm{CDCl}_{3}\right)$ of compound 15 


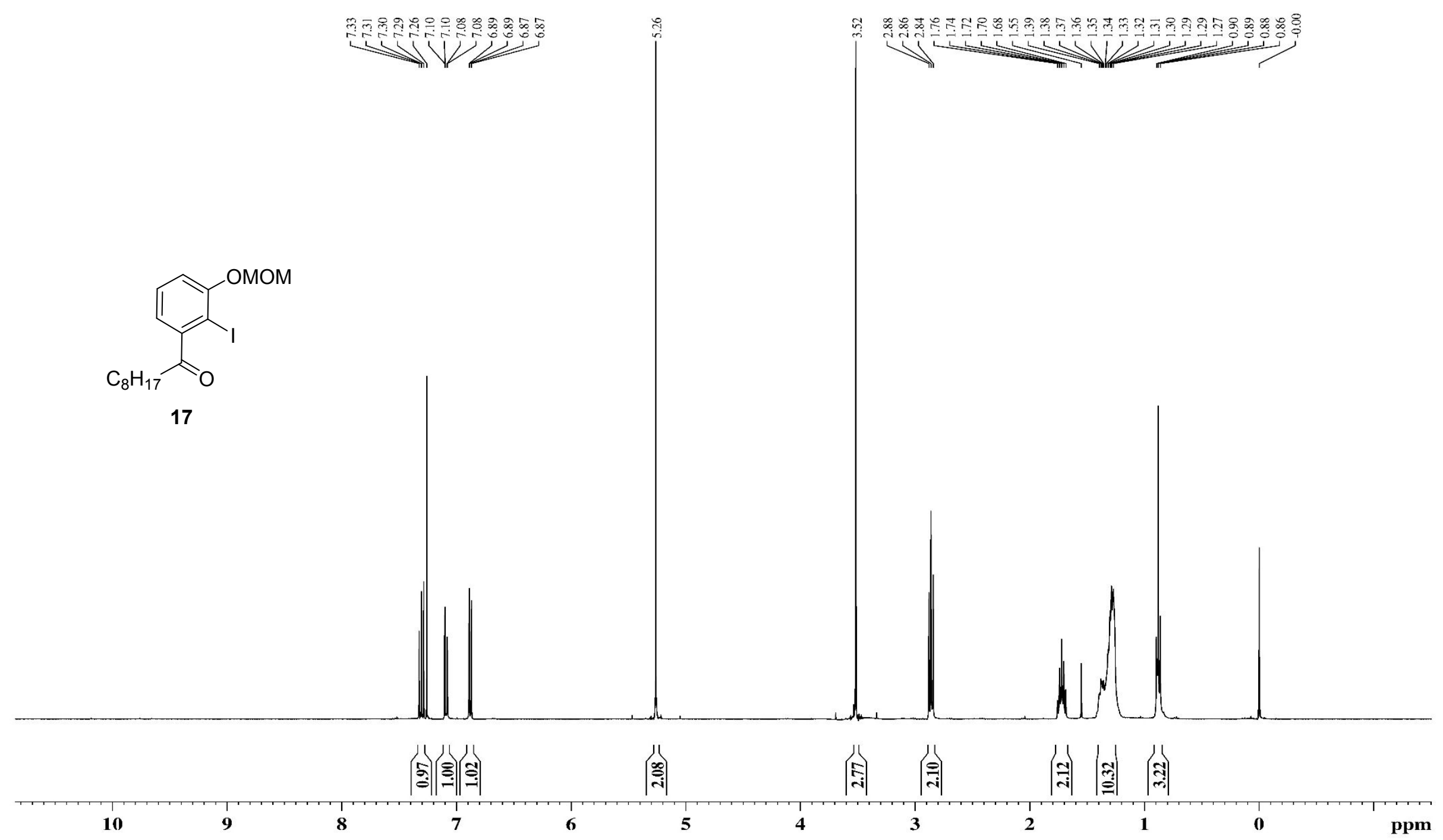

Figure S13. ${ }^{1} \mathrm{H}$ NMR spectrum $\left(400 \mathrm{MHz}, \mathrm{CDCl}_{3}\right.$ ) of compound 17 

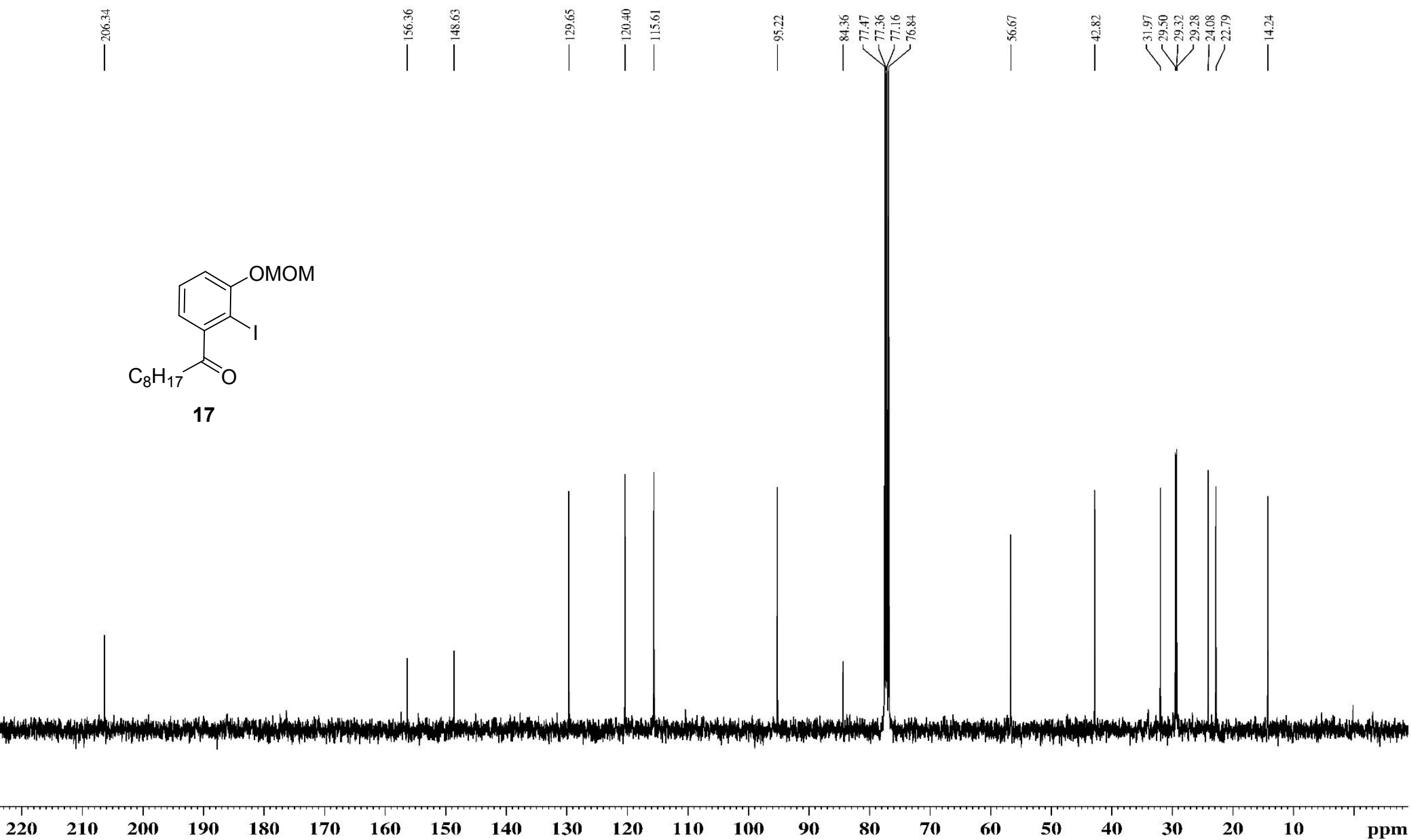

Figure S14. ${ }^{13} \mathrm{C}$ NMR spectrum $\left(100 \mathrm{MHz}, \mathrm{CDCl}_{3}\right)$ of compound 17 


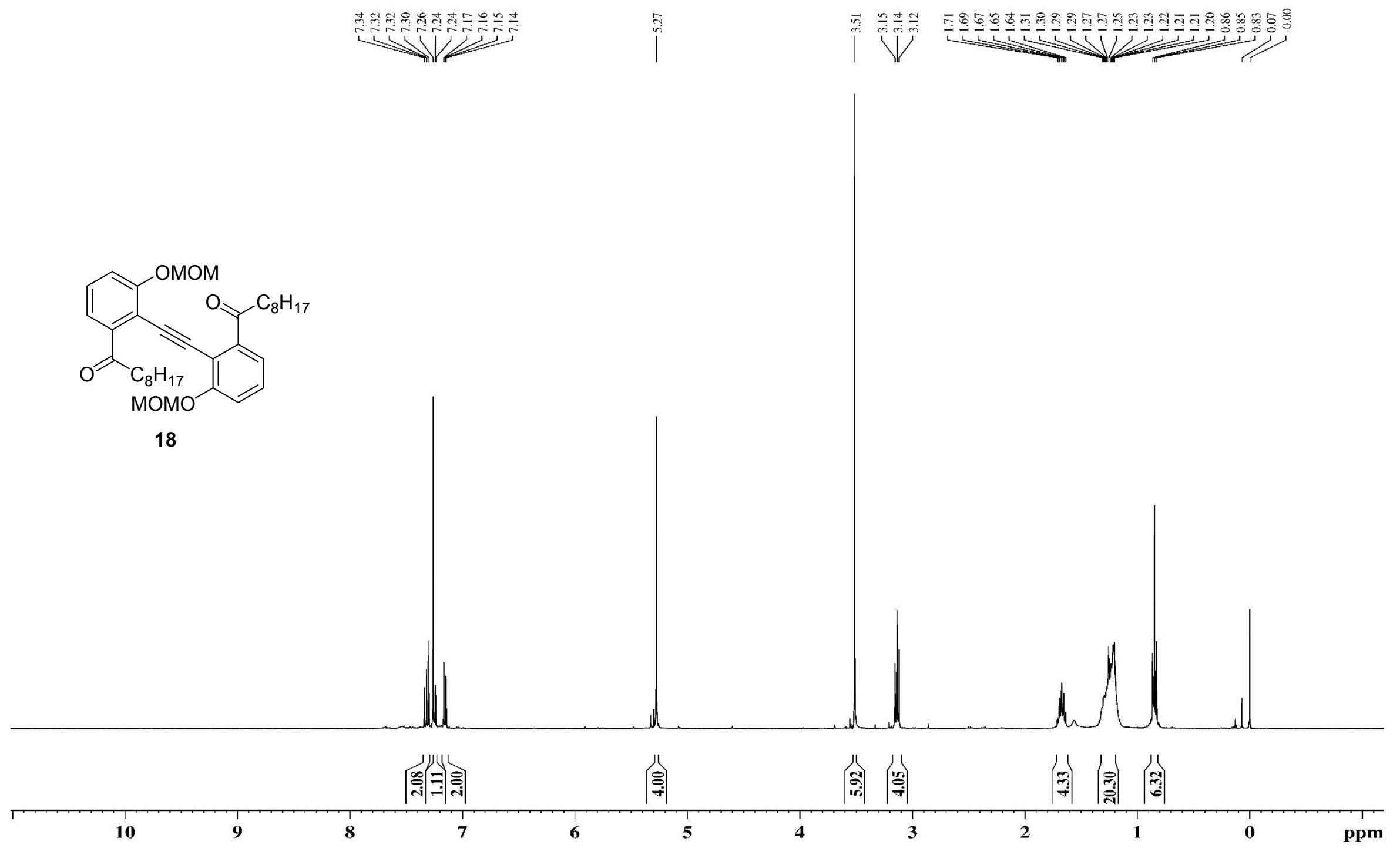

Figure S15. ${ }^{1} \mathrm{H}$ NMR spectrum $\left(400 \mathrm{MHz}, \mathrm{CDCl}_{3}\right)$ of compound 18 


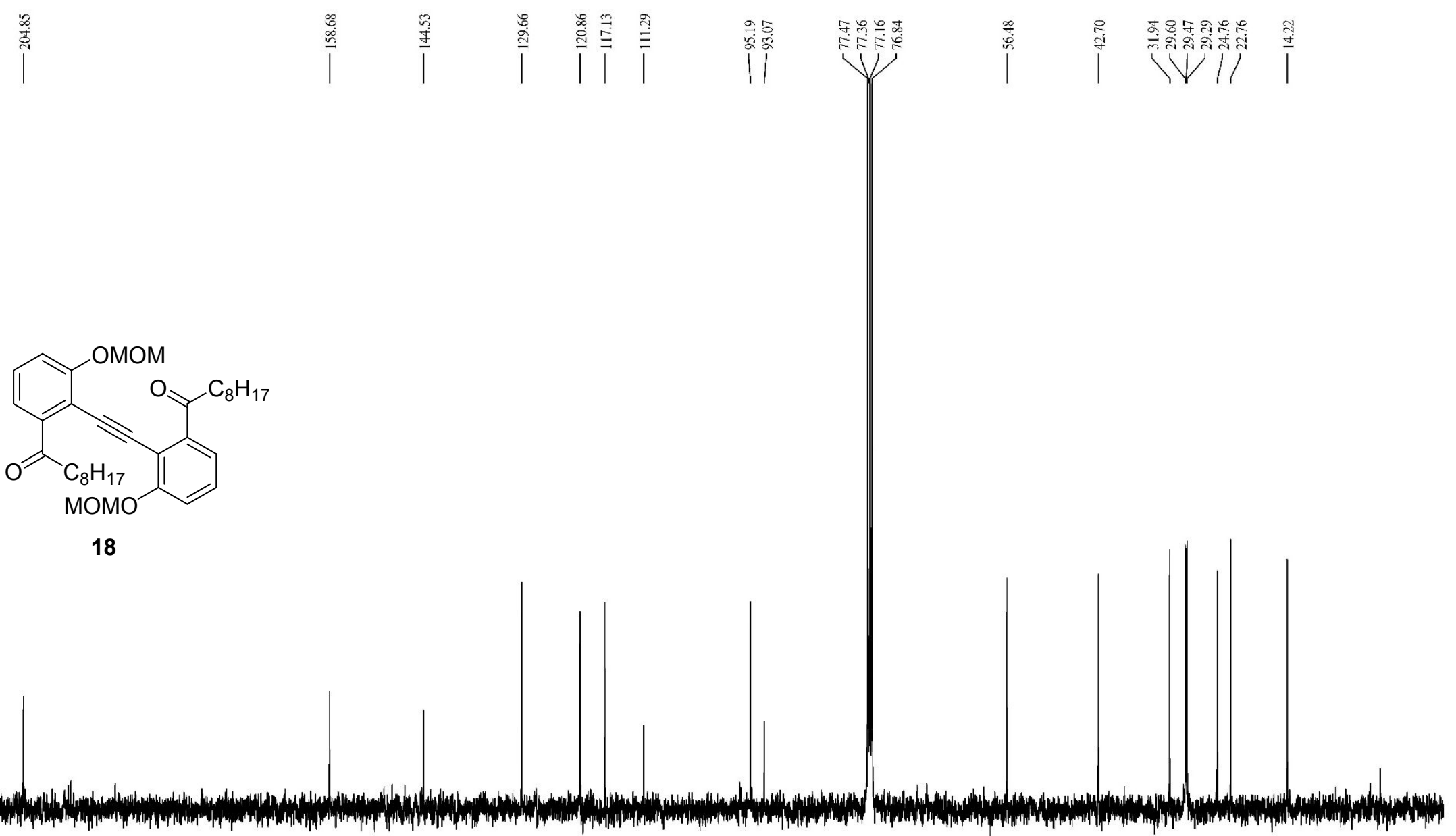

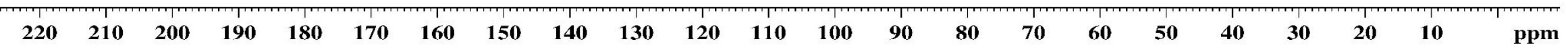

Figure S16. ${ }^{13} \mathrm{C}$ NMR spectrum $\left(100 \mathrm{MHz}, \mathrm{CDCl}_{3}\right)$ of compound 18 


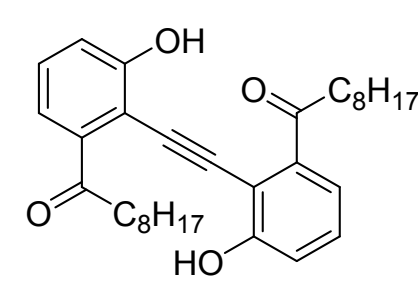

11

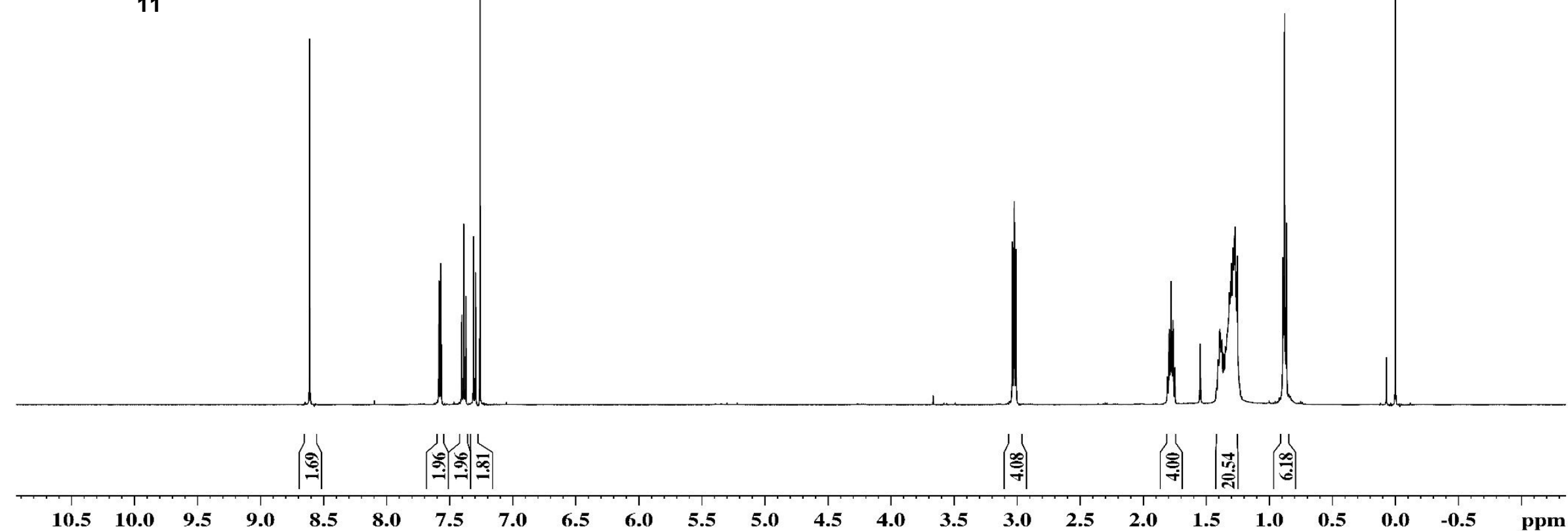

Figure S17. ${ }^{1} \mathrm{H}$ NMR spectrum $\left(500 \mathrm{MHz}, \mathrm{CDCl}_{3}\right)$ of compound 11 


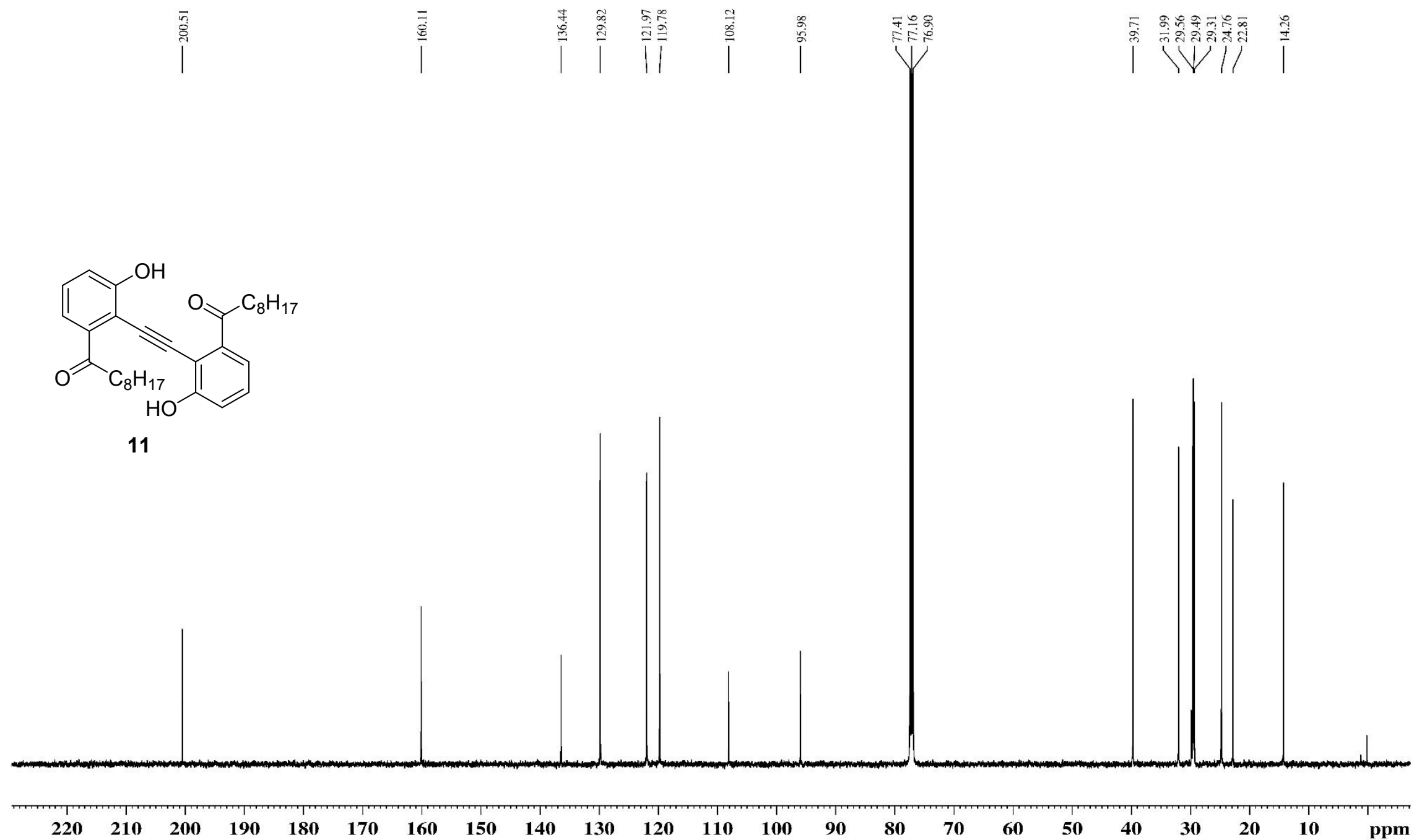

Figure S18. ${ }^{13} \mathrm{C}$ NMR spectrum $\left(125 \mathrm{MHz}, \mathrm{CDCl}_{3}\right)$ of compound 11 


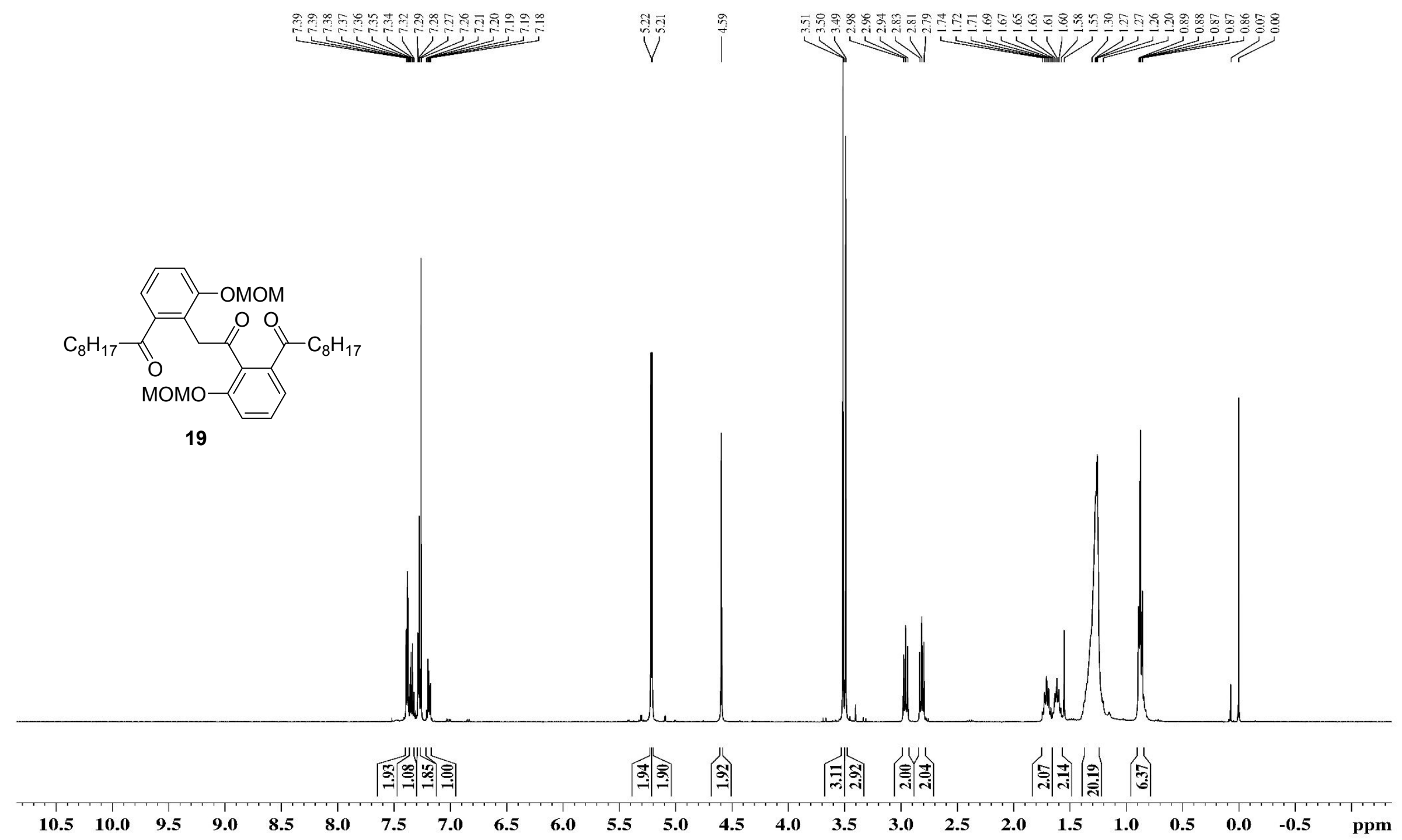

Figure S19. ${ }^{1} \mathrm{H}$ NMR spectrum ( $400 \mathrm{MHz}, \mathrm{CDCl}_{3}$ ) of compound 19 


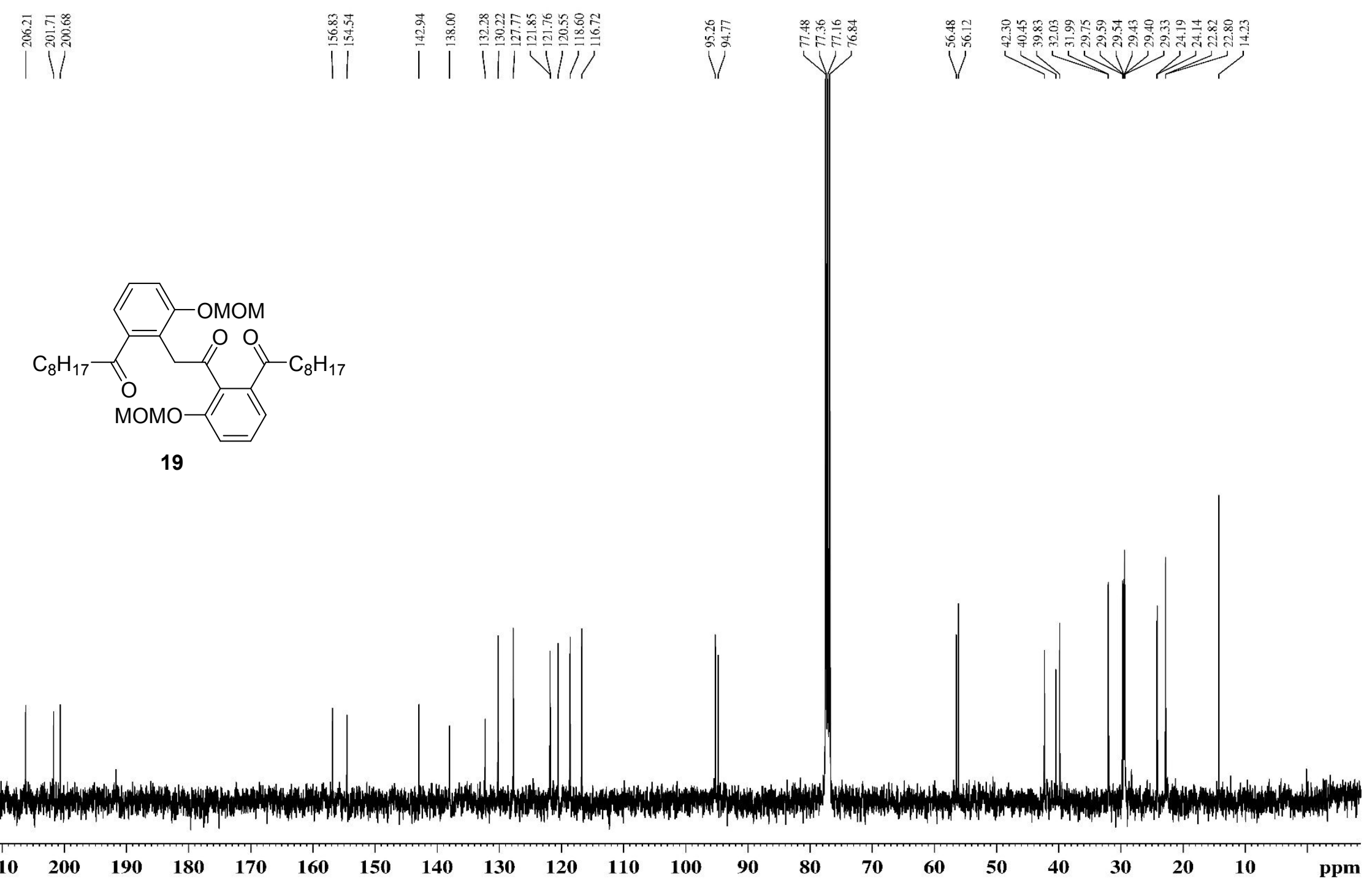

Figure S20. ${ }^{13} \mathrm{C}$ NMR spectrum $\left(100 \mathrm{MHz}, \mathrm{CDCl}_{3}\right)$ of compound 19 


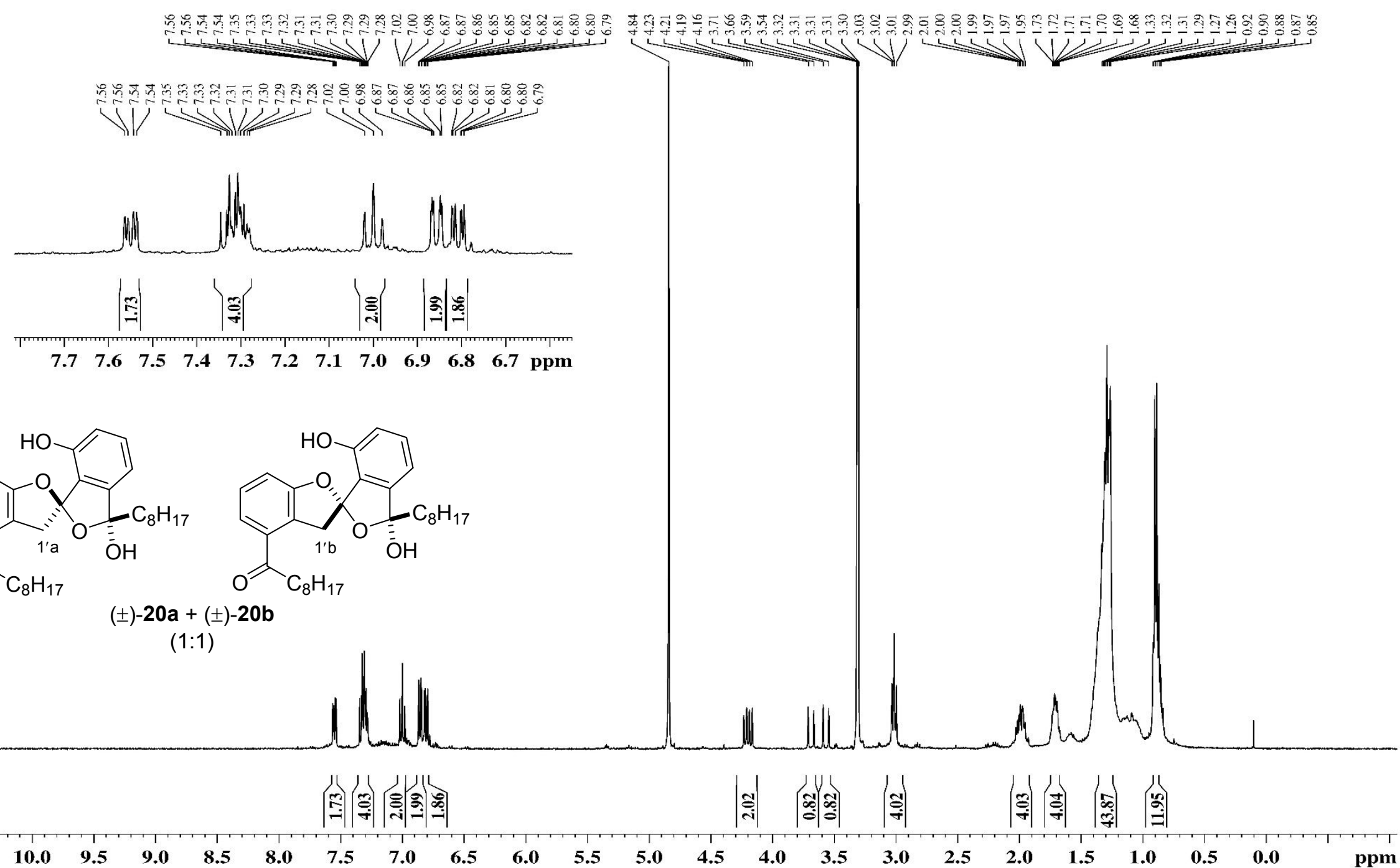

Figure S21. ${ }^{1} \mathrm{H}$ NMR spectrum (400 MHz, methanol- $\left.\mathrm{d}_{4}\right)$ of compound ( $\mathrm{rac}$ )-20 


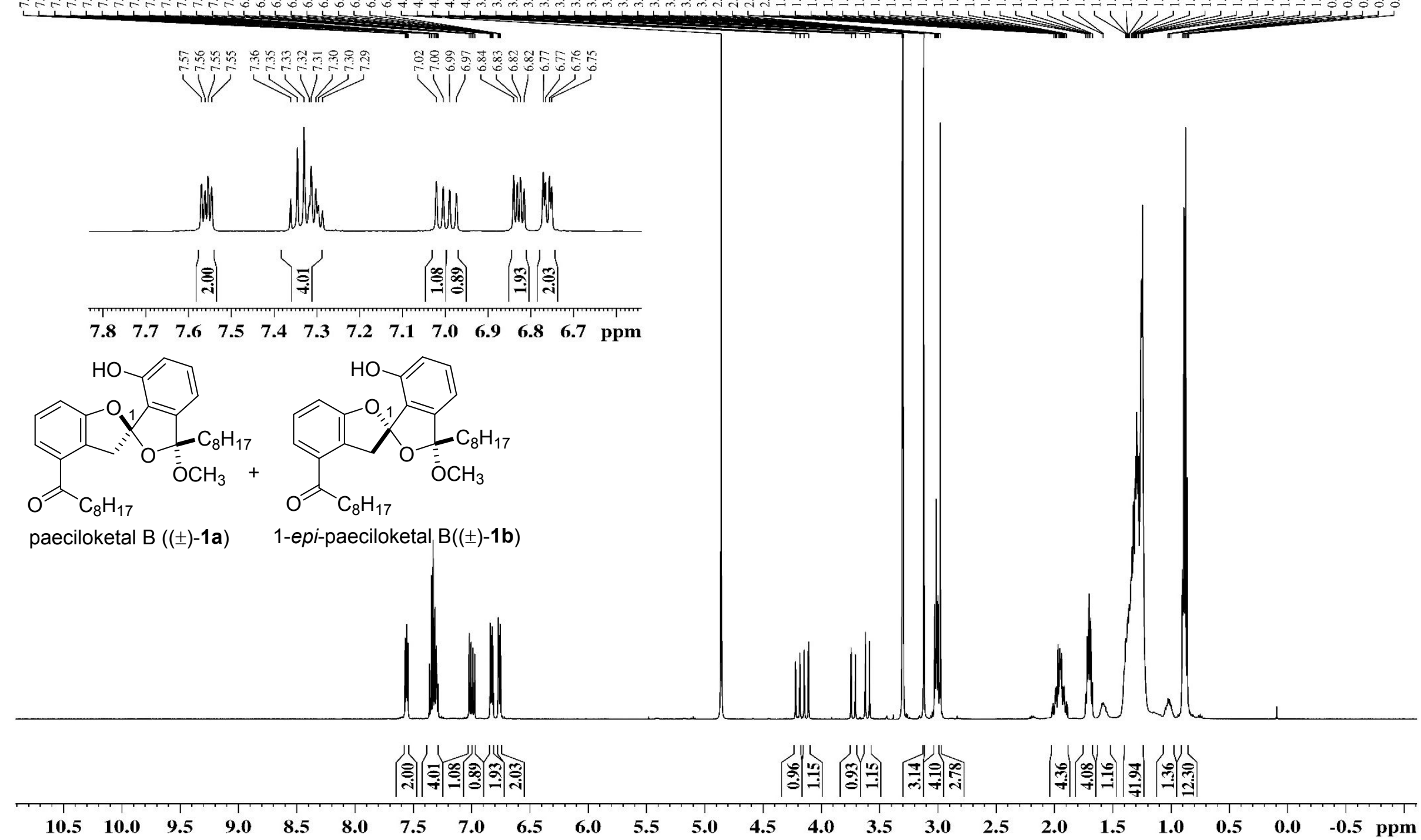

Figure S22. ${ }^{1} \mathrm{H}$ NMR spectrum $\left(500 \mathrm{MHz}\right.$, methanol- $\left.\mathrm{d}_{4}\right)$ of paeciloketals $( \pm)-\mathbf{1 a}$ and $( \pm)-\mathbf{1 b}(11: 14)$ 

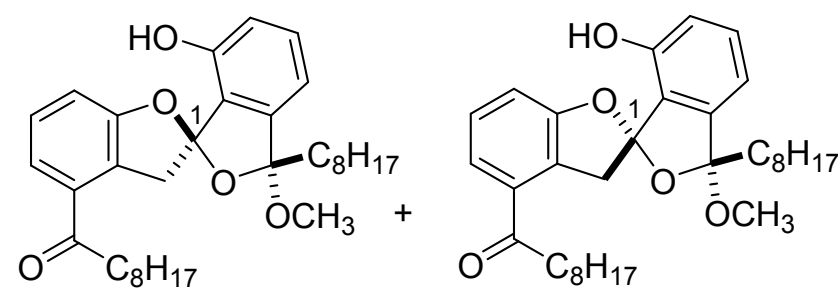

paeciloketal $B(( \pm)-1 \mathbf{a})$

1-epi-paeciloketal $\mathrm{B}(( \pm)-\mathbf{1 b})$
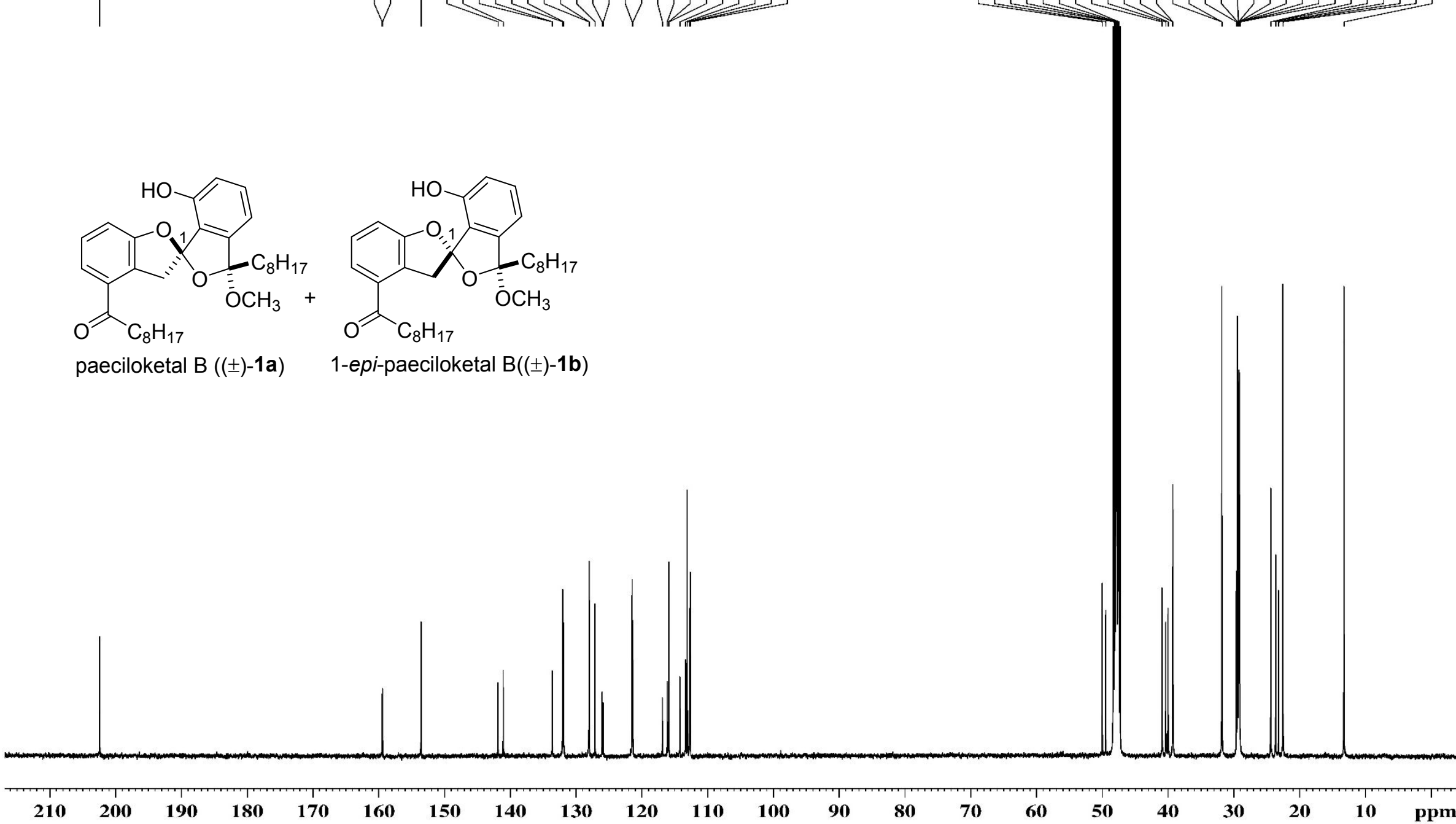

100

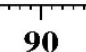

80

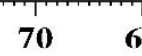

60

50 40

30

20

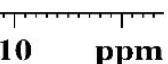

Figure S23. ${ }^{13} \mathrm{C}$ NMR spectrum $\left(125 \mathrm{MHz}\right.$, methanol- $\left.\mathrm{d}_{4}\right)$ of paeciloketals $( \pm)$-1a and $( \pm)-\mathbf{1 b}(11: 14)$ 


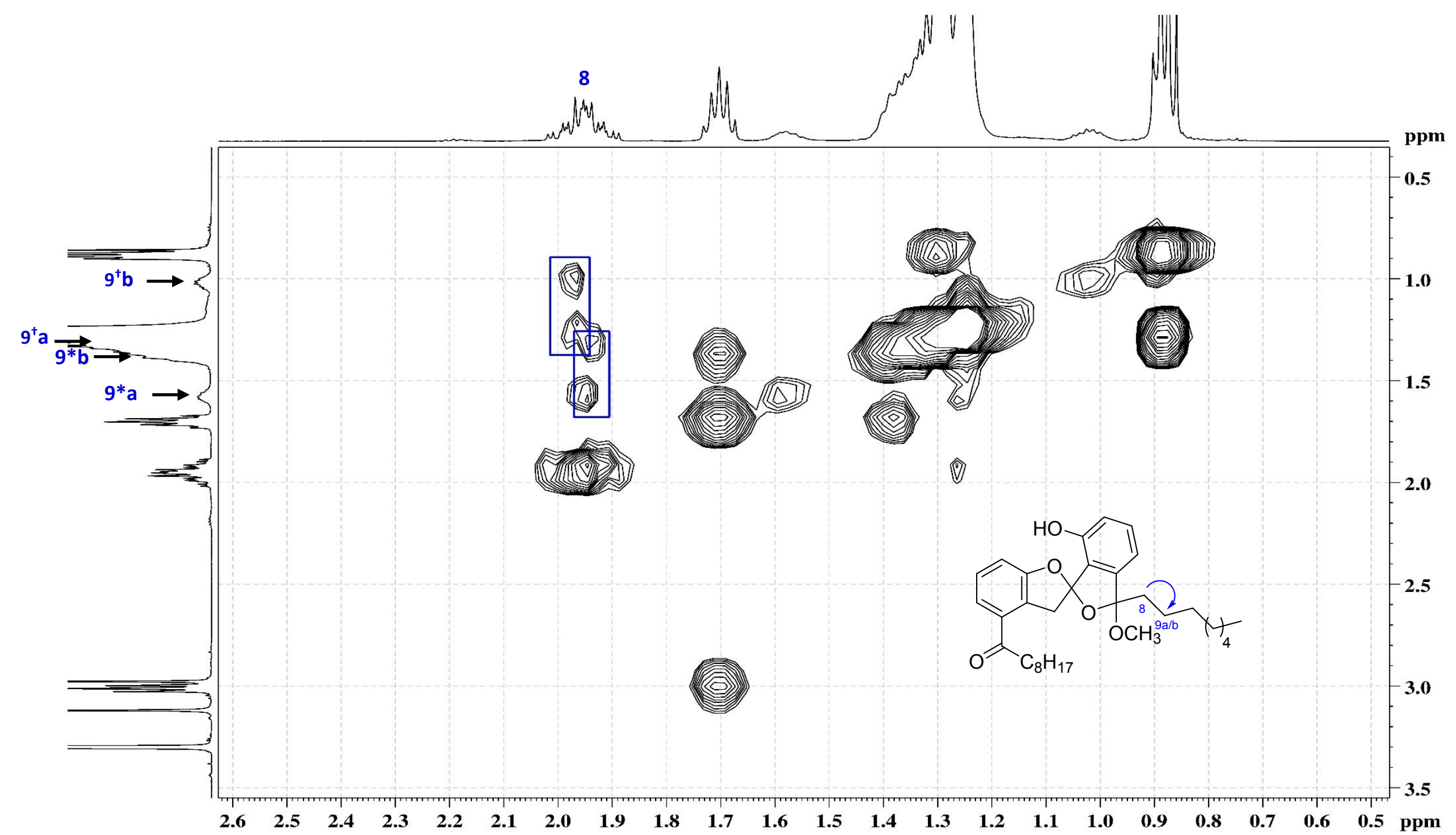

Figure S24. COSY spectrum (500 MHz, methanol-d $\left.\mathrm{d}_{4}\right)$ of paeciloketals $( \pm)-\mathbf{1 a}$ and $( \pm)-\mathbf{1 b}(11: 14)$ 


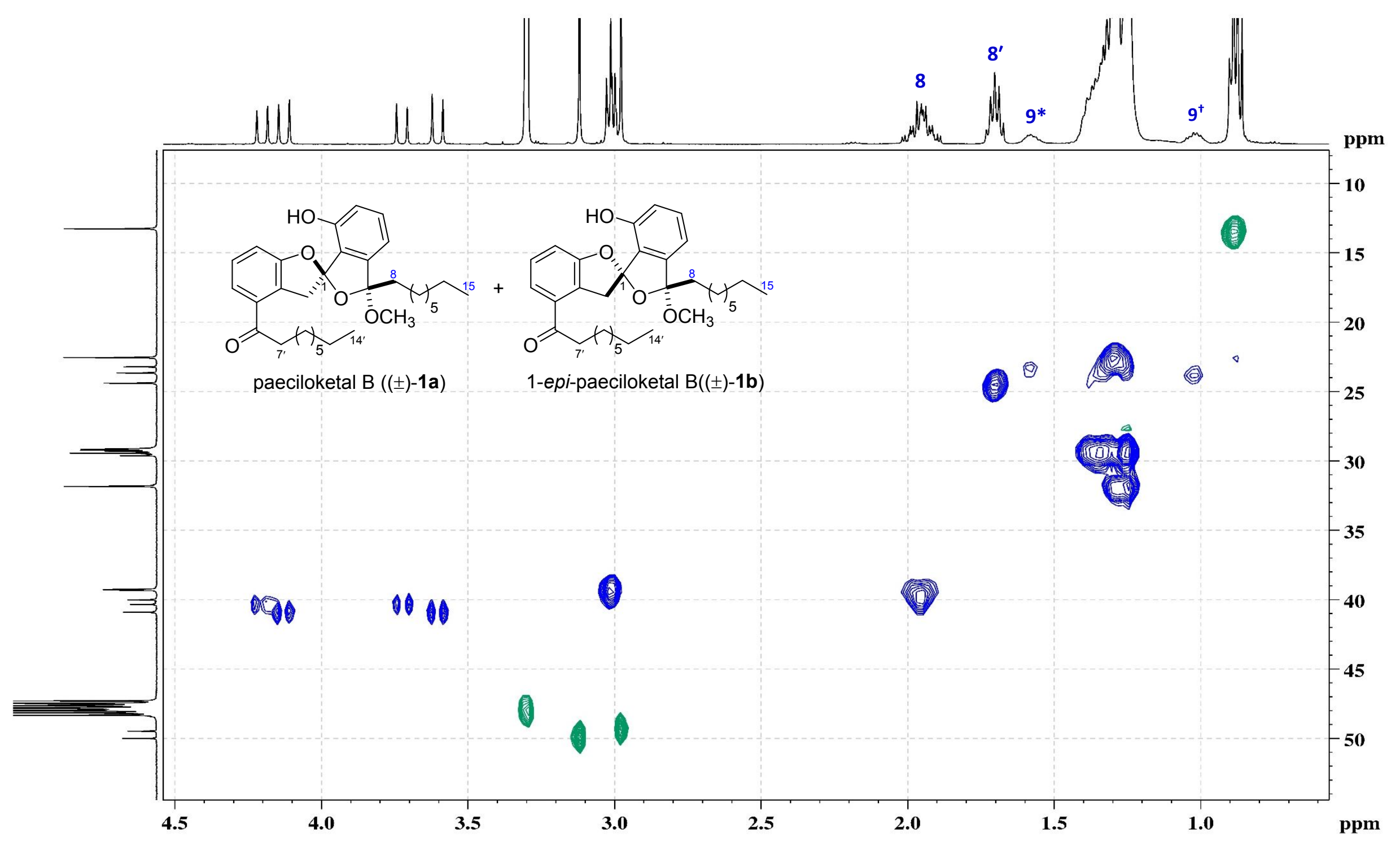

Figure S25. edited-HSQC spectrum (methanol- $\left.\mathrm{d}_{4}\right)$ of paeciloketals $( \pm)-\mathbf{1 a}$ and $( \pm)-\mathbf{1 b}(11: 14)$ 